\title{
Power Markets of Asian Countries in the International Markets Environment
}

This Chapter deals with the current state and problems of power markets in Asian countries in the international market environment. The process of restructuring the electric power industry and forming power markets in the world has almost a twenty-year history. Certain experience has been gained that reflects both the positive effects of market transformations in the electric power industry and some problems. Power markets in Asian countries are formed on the basis of world experience. However, in different countries this process progresses at different paces. Generalization of the experience in market transformations in the electric power industries of Asian countries, analysis of the benefits, and risks that may occur as a result of such transformations will help specialists solve the problems encountered in their countries.

\subsection{Development Of Power Market In India}

At the time of independence in 1947, the Indian power sector was merely concentrated in and around a few towns and urban areas to meet the need. In the following decade, it saw development of massive river-valley projects that led to some form of limited interconnected systems to provide power to the population along particular belts as a side-by-side benefit to the effort made for irrigation for agricultural need and flood control. However, the nineteen sixties gave proper status to development of the power sector both in terms of generating unit sizes and transmission voltage due to the requirement of rapid industrial development. This called for integration and evolution of the state grids. Attempt to join these grids to form the five regional grids became successful by the nineteen seventies and eighties with unit sizes going from 210 to $500 \mathrm{MW}$ and transmission voltage from 220 to $400 \mathrm{kV}$ as a consequence of transfer of a large amount of power from coal pit-head (mine-mouth) thermal power stations to urban conglomerations. Subsequent scenario of the power sector in the nineteen nineties and beyond has been quite bright from the point of view of development of HVDC systems, incorporated both for bulk power supply over a large distance up to about $1370 \mathrm{~km}$, be it within a large state or region or for inter-regional transfer of power, and also for inter-regional back-to-back connection for limited transfer of power. Side by side to this, the sector was unbundled with the recognition of generation, transmission and distribution as separate and distinct activities so far as the power supply system is concerned. Both at state level and central level regulatory commissions were formed to decide tariff, grid code, etc. With opening up, the sector experienced participation of the private sector entities, mainly in generation and then to some extent in distribution. Transmission still remains a monopoly, with public holding terming it as State Transmission Utility (STU) or Central Transmission Utility (CTU) depending upon whether it belongs to any state or center. With Central Electricity Regulation Commission (CERC) permitting open access to 
the inter-state transmission facility from November 2003 [1], it opened vistas of power trading by state-owned companies or private traders or joint sector venture. It was an important step after promulgation of the Electricity Act 2003 [2]. Activities that followed and aimed at influencing scheduling and real time grid operation with pseudo Power Exchange [3] in place definitely pave the way for healthy trading in power. This is unlike other commodities in market. Electricity cannot be stored in its form and hence calls for supply-demand matching at every instant of time. Section 16.1 gives the status of such trading prevalent in India considering the market related to energy, generation capacity, transmission capacity and ancillary services one by one. Also, with the development in neighboring countries, the possibility of power and energy trading is examined.

\subsubsection{Energy Market}

For the Indian power sector, the bilateral energy market is on the basis of long term, shortterm, day-ahead or intra-day commitments. With measurements logged at 15-minute intervals, a weekly cycle of settlement of energy is carried out. This is based on before the fact commitments at mutually agreed terms, but taking into account deviations settled at frequency actuated dynamic rate known as the Unscheduled Interchange (UI) rate [3]. However, the process has excessive reliance on the UI mechanism, though regulatory caps restrict the rate. The trend is encouraging with consensus being built for an organized market in this respect in the form of Power Exchange (PEX).

\subsubsection{Generation Capacity Market}

As one goes back in history, typically under Central Government regional power stations [termed as Inter-State Generating Stations (ISGS) (be it thermal - fossil fired or gas-based, hydro or nuclear)] established at different times have a common basis of sharing of power amongst the beneficiary states of the concerned region. An allocation is made of $85 \%$ of the installed capacity of the station by that procedure. Hence the capacity may be thought of as locked up in long-term bilateral contract between the producer and consuming states. The remaining $15 \%$ floating capacity is highly sought after during peak demand and it keeps changing hands subject to negotiating skill and political networking of the beneficiary causing a considerable amount of heartburning for the losers. What started as a flexibility margin to accommodate the seasonal demand pattern has degenerated into a discretionary instrument.

On the other hand, lackluster participation of private players in capacity addition (generation and transmission) could be attributed to lack of an organized capacity market. However, hope exists due to stray examples of capacity trade. One such case is with the Power Trading Corporation (PTC) brokering the sale of royalty share of the Himachal Pradesh State Electricity Board (HPSEB) in the Nathpa-Jhakri Hydro-Electric Project to Punjab State Electricity Board (PSEB) for the summer months.

\subsubsection{Transmission Capacity Market}

The Central Electricity Authority, an apex technical body of Government of India in the power sector, carries out perspective planning as a whole. With the data collected through load survey by its regional units in collaboration with the state electric utilities, long termload forecasting is done. Based on the same matching, generation is formulated through the 
integrated resource planning approach identifying generation location and possible corridor for transmission of power from source to load. Thereafter, studies are performed to configure in detail the network for evacuation of power from the generating stations and consequent strengthening of the existing network, if required, with the level of voltage chosen with a view to have an adequate margin for future expansion. Transmission capacity expansion so planned is then deliberated in the Standing Committees region-wise through a consultative procedure to identify the utilities to build, own and operate the relevant expansions.

Accordingly, with the transmission system still being totally need-based and enjoying natural monopoly, the pricing is tightly aligned to long-term capacity allocations. Though open access is in vogue, in reality it has not been segregated yet as an independent facility under the fear of jeopardizing the existing setup. On the other hand, lack of addition may result in congestion sometime at some pockets during grid operation, Consequently, its management is totally based on the discretion of the concerned Regional Load Dispatching Center (RLDC). The long-term transactions have priority over short-term transactions. The RLDCs have discretionary powers over interstate dispatch and load regulation. Inter-regional (Pool to Pool) unscheduled interchange transactions are then used for easing congestion.

\subsubsection{Ancillary Services Market}

Ancillary Services are defined as those services that are necessary to maintain reliable operation of the interconnected / integrated transmission system. These services are required to effect a transaction. It includes reactive power and voltage control, loss compensation, scheduling, dispatch and settlement, load following, system protection, energy imbalance and black start facilities. In India a lot of work needs to be done in this area as described below.

\section{Load Following-Primary Response}

- Free Governing Mode Operation (FGMO) is mandatory as per grid code.

- Issue is diluted / scuttled under the garb of technical jargon / issues put forth by generators.

- Services are basically not priced and implicitly paid through capacity charges. Therefore, there is no incentive for Independent Power Producers (IPP).

- Frequency linked dispatch guidelines are for secondary response.

\section{Voltage Control}

- Reactive drawl and injection at interstate exchange points are priced.

- It is a simple mechanism. Issues in treatment are virtually of residual amount.

- Generators are not paid and very often they take refuge under a conservative machine capability curve.

\section{Loss Apportionment}

- Losses are shared by long-term customers in ratio of their subscriptions in ISGS.

- All energy transactions are discounted by estimated losses during scheduling.

- There is regulatory intent of moving towards the concept of incremental losses. 
Scheduling and Dispatch

- $\quad$ RLDC coordinates as well as implements inter-utility contracts.

- Decentralized resource scheduling is in vogue with state load serving utilities having full operation autonomy of dispatching their generation resources.

- Though as per grid code there is a provision for $5 \%$ spinning reserve, due to perpetual shortage, in reality implementation has not been possible yet.

- Well-defined timeline exists for declaration of availability and requisitioning of energy up to capacity subscriptions of the shareholders.

- Expenses clubbed under the RLDC Operation and Maintenance (O\&M) head is paid by long-term constituents only.

- At present a sum of Indian Rupees (INR) 3,000 / day/ transaction is charged for scheduling open access transactions.

- Inter utility settlement statement (Regional Energy Accounting taking care of UI and Reactive Accounting) is issued by the Central Pool Administrator. Capacity and energy charges are settled mutually while the unscheduled and reactive energy settlement is routed through a pool.

\section{System Protection}

Protection Coordination Committee (PCC) decides

- Equipment protection coordination at the regional level.

- $\quad$ System monitoring and supervision is carried out by RLDC.

Energy Imbalance

- It is addressed through unscheduled interchange mechanism.

- Weekly settlement cycle based on above is in vogue.

- It is the discretion of concerned RLDCs for arbitrage across asynchronous (HVDC) links.

\section{Black Start}

- It is purely voluntary.

- It is well documented under Regional Black Start Procedures.

- UI mechanism is suspended during period of disturbance and actual transaction is treated as schedule.

\subsubsection{Possible Power and Energy Trading with Neighboring Countries}

India is surrounded by the countries Nepal, Bhutan, Bangladesh, Srilanka. Pakistan creates major prospect in South Asia for trading in power and energy due to disposition of natural resources of different kinds for mutual benefits of all. Nepal and Bhutan are rich in Hydro resources, Bangladesh is rich in gas reserves and India is rich in coal resources, thus providing promising option for cooperation among countries. India can emerge as the main potential power / gas export market for the neighboring countries. Generation can be at source and trading through electrical interconnection. India can supply coal to the neighboring countries and can import gas from Bangladesh.

Issues to be addressed in the process of development are investment capabilities, lack of market information, viability of buyers, inadequacies in institutional mechanism, environment 
and social concerns. Cross border trading in electricity has technical considerations as well as political and economic ones. Pricing should be such that both sides benefit. For example, if one party has a lot of inexpensive hydropower, during monsoon seasons then it may benefit from selling it at lower price to a neighbor rather than having the water spill. There is necessity of a larger perspective while planning through an integrated approach for the entire SAARC (South Asian Association for Regional Cooperation) region. Both Generation capacity and Transmission interconnection capacity are to be enhanced. To be adopted is common principle / methodology for tariff determination, operational protocol, security / reliability and regulation. To be evolved also is the Contractual Agreement that addresses principal obligations that are equitable, risk sharing, issues related to financial and payment, commercial and legal, dispute resolution and arbitration.

Therefore, prerequisites for Regional Power Pool (RPP) may be summarized as -

- Technical solutions not difficult but Political will of the member countries important

- A cooperative mindset

-Willingness to reconnect the subcontinent

-Efforts to build trust / sensitize

-Greater sensitivities to issues

- A commitment from the member countries for

-Resources / manpower

-Reciprocal measures

- Success of Bilateral exchange will create the ground for multi-lateral exchange

- Regional economic prosperity should take precedence over political compulsion.

Thus, it is in the nascent stage, there is lot of promises in power trading in India with the participation of a number of players from public or private or joint holding companies. Permission for open access really has created opportunities for improving supply system through competition in terms of overall economy as well as ultimate efficiency. With the typical characteristic of the commodity (power) in the market that in its normal form cannot be stored and at every instant supply-demand matching is called for, inherent risk dictates necessity of well-laid principles of practices to be followed for short-term, mid-term and long-term contracts.

So far as power and energy trading with neighboring countries is concerned, presently power trading is based on bilateral agreements and although Energy Ring is high in SAARC agenda, the progress has remained slow. The strategies for promotion of trading can be through carrying out sector reforms, setting up suitable institutional arrangements, joint investment in project including Environment Impact Assessment (EIA), private sector participation, long term transmission planning and free exchange of information.

\subsection{Russia's Power Industry Restructuring Current State And Problems}

Russia's power industry is on the way to radical structural and managerial reformations. Reduction in electricity demand in the early 1990s provided good conditions for structural and managerial changes in the industry. However, the country is facing new industrial growth and the favorable period of excessive generation is coming to an end. The industry needs fast and effective reforms for economic efficiency improvements and investment 
attraction. This Section reviews the restructuring policy and describes the current state and development of a competitive environment in the Russian power industry.

Russia is an Eurasian country, and only about 30\% of the power industry locates in its Asian part (in Siberia and Far East). But restructuring ideology is the same for each part of Russia. Therefore, the power industry state and restructuring will be considered in Russia as whole.

\subsubsection{Technical Characteristics of the Russian Power Industry}

The main distinctions of the industry are long-distant electricity transmission, unevenly allocated energy resources as well as electricity generation and consumption over vast territory.

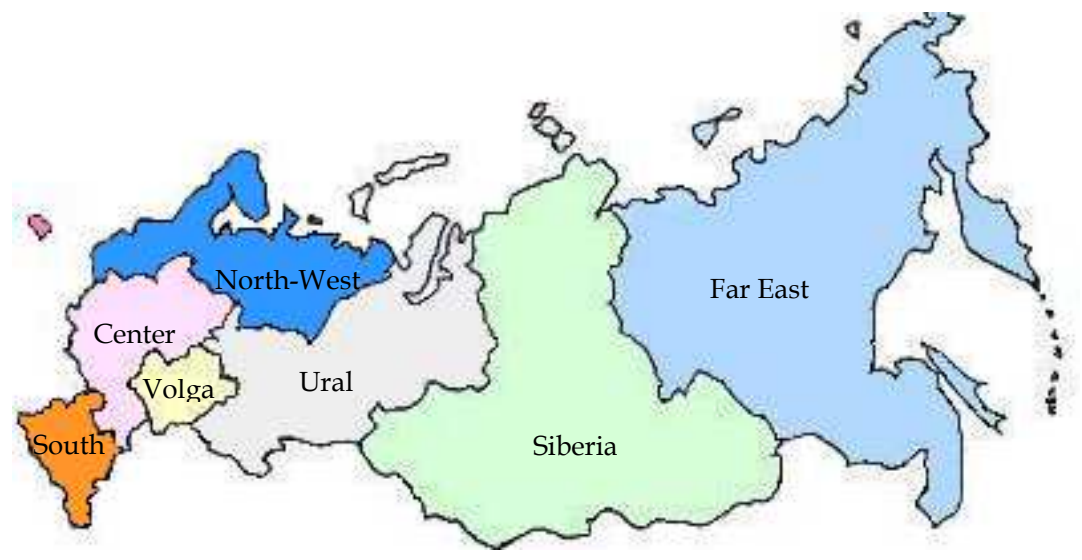

Figure 16.1. Interconnected power systems in UES of Russia

The Unified Electric System (UES) in Russia is still operating as a single complex. There are 77 local utilities combined into 7 regional interconnected power systems [4-6] (Figure 16.1). Six of them (excluding the Far East) operate synchronously. The transmission network covers six time zones, which helps reduce the peak demand by $6 \%$.

The Russian power industry had 219.2 GW of installed capacity up to the beginning of 2005, including 805.2 GW running synchronously within UES. 14.0 GW ran separately from UES in the Russian Far East and in the Arctic regions of the country. Taking into account dismantling units the industry had a slight growth of generating capacities in 1999 and a slight decrease in 2000.

All power plants in Russia generated a total of 953,100.0 GWh of electricity in 2005 including $340,700.0 \mathrm{GWh}$ within UES. Thermal power plants on organic fuels generated $629,200.0$ GWh or $66 \%$ of total production. Hydropower plants generated $174,400 \mathrm{GWh}(18.3 \%)$ and nuclear power plants produced 149,500.0 GWh (15.7\%).

The peak of electricity demand in 2005 in UES was registered on January 26 at 6 p.m. and reached $128.7 \mathrm{GW}$. The total excess of generating capacity in UES was $63.5 \mathrm{GW}$ or $33 \%$ of installed amount. However, not all installed capacity could be used at peak hours. In winter 
2005-2006 only 170 GW of generating capacity was available for operation. Taking into account a necessary capacity reserve of $21.4 \mathrm{GW}$ (16.6\% of maximum demand) the actual excess of capacity in Russia is 19.9 GW or $9.7 \%$ of available amount. UES of Russia supplies electricity to several countries in Europe and Asia (Figure 16.2).

$12.5 \%$ of total generation was lost in the transmission and distribution networks. The annual electricity consumption grew by $4 \%$ in 2000 and $2.5 \%$ in $2001-2005$.

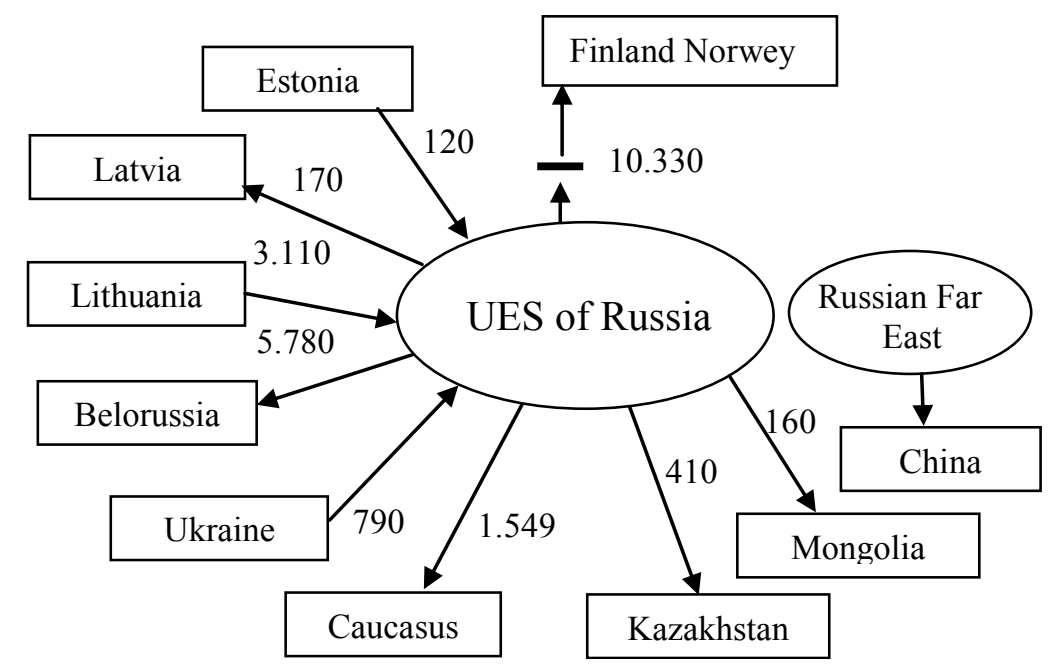

Figure 16.2. Export and import of electricity in 2005, GWh

\subsubsection{First Steps of Restructuring}

The restructuring process was launched in 1992 [4]. The ownership pattern was changed and the existing State-owned local utilities were rearranged into joint stock companies. Nuclear power plants with a total installed capacity of $21 \mathrm{GW}$ were left under State control.

The joint stock company RAO "UES of Russia" was established in 1992 as a new managerial holding. 34 large power plants with a capacity of 57 GW (approximately $27 \%$ of total generating capacity) were withdrawn from local utilities to reduce the monopoly in power generation and became the property of RAO "UES of Russia". Also, the decision was made to concentrate the transmission network in RAO "UES of Russia" as well as Central and Regional Dispatching Offices. It was supposed that each new local utility had to delegate no less than $49 \%$ of its shares to the holding. The RAO was commissioned to set up and operate a wholesale market both technologically and commercially. Actually, not all the utilities delegated this percentage of their shares to the RAO. Nevertheless, RAO "UES of Russia" acquired too much property and authority.

Today RAO "UES of Russia" is the monopoly in the field of energy supply and is the financial and industrial holding, which consists of a number of regional power utilities, large federal power stations and intersystem electric grid. The State owns the controlling stake of 
the RAO. The Government appoints both the Board of Directors and the Chief Executive of the RAO. It regulates all activities of the energy holding and regulates the prices of its services and production.

Two kinds of electricity markets were established in the 1990s - the nationwide wholesale market and the local retail ones. Electricity prices for power producers on the wholesale and retail markets were fully regulated and set on the "cost plus" principle.

Large power plants, which were withdrawn from the utilities, nuclear power plants and local utilities with generation surplus could sell their electricity to utilities with deficient generation on the wholesale market. A few large industrial customers got the right to participate on the wholesale market. Each local utility had a choice either to generate power locally or to buy it on the wholesale market. The retail markets were established primarily within the territories under service of the local utilities and had to supply their end customers. The responsibility for the wholesale market operation was delegated to RAO "UES of Russia". The responsibility for retail market operation was imposed on the local utilities that provided distribution and customer services.

Wholesale electricity prices in Russia were based on generation and transmission costs. The Federal Energy Commission regulated the costs and profits of producers on the wholesale market under control of the Federal Government. The costs of utilities and prices on the retail markets were subject to regulation by Local Energy Commissions under control of local Governments. Electricity prices for the wholesale and retail customers were set as blanket (weighted average) prices calculated as a ratio of electricity cost to volume of electricity to be purchased. The prices on both the wholesale and retail markets were adjusted on a quarterly basis.

RAO "UES of Russia" was an operator on the wholesale market. It bought, as a single trade agent, electricity from producers using the pay-as-cost principle and sold electricity to the utilities at a blanket (average) price. The electricity price, additionally to the generation expenses, included transportation, operation and investment components. The same approach was used on local retail markets. The prices on the wholesale market were differentiated with respect to price zones according to the transportation and congestion costs. The prices on the retail markets were differentiated with respect to consumer groups, such as large industrial, small industrial, agricultural, residential and others.

Up to the middle of 2003 prices increased by 1.5-1.7 times [5]. Average prices greatly differ in the Siberian and Far-Eastern regions. There are cross subsidies between different groups of consumers. In most regions (except Urals and Siberia) industrial consumers pay above the average price, while rural residential consumers (except Siberia) pay less.

The funds for generation and transmission expansion were mostly filled up through the regulated investment component of wholesale prices. The funds for development of power plants and distribution networks that belong to local utilities were filled up through the regulated component of retail prices. 
After the first steps of restructuring the situation in the power Industry remained very tense [4]. First of all, the UPS badly needed new investments. Financial injections into the industry were 56 times less than was required. This resulted in dangerous aging of generating and transmitting facilities. Nearly half the existing infrastructure exceeded its intended service life [7].

The efficiency of electricity and heat production decreased. Auxiliary electricity consumption in power plants together with electricity losses in networks increased to $23 \%$ in 1998 in comparison with $17 \%$ in 1991 . The fuel component of electricity cost increased by $11 \%$ in the 1990 s. The relative annual profit of the industry fell down from $25.5 \%$ in 1993 to $11.3 \%$ in 1999. This led to a hard and unstable financial condition for most of the local power utilities.

A huge debt of customers (more than $\$ 4.3$ billion) was accumulated in the 1990s. The debt was comparable with the annual income of RAO "UES of Russia". For years, the industry subsidized the Russian economy by supplying the electricity and heat to non-paying customers. A large portion of payments was accepted in barter and mutual debt write-offs. The situation with non-payment was improved considerably in 1998-99 as payments in money rose to $90 \%$. But the accumulated debts pulled the industry down and did not allow local utilities to develop their generating and network facilities.

Wholesale and retail markets in Russia were highly regulated. However, the system of the State regulation was not effective. The pricing mechanism on the wholesale market was obsolete and did not encourage cost reduction. The regulation on local retail markets fell hostage to local governments and politicians. Electricity prices were too low (see Table 16.2) and did not often compensate even for the production costs. It led to generation reduction and consumer cut-offs. The legislation in the industry remained far behind the current needs.

Unreliable fuel supply was an urgent problem for the industry. Coal miners and natural gas suppliers did not provide power plants with enough fuel because the power plants and utilities often failed to pay for the fuel in time. This resulted in dangerous situations on some territories of Siberia and the Far East of Russia, particularly in the severe winter of 2001 when electricity and heat supply was interruptible. Unreliable fuel provision led to ineffective generating unit commitment.

Most experts considered the situation in the Russian power industry dangerous. In any case, the industry needed radical and wide-scale reforms based on the interests of different parties in the society.

\subsubsection{A New Stage of Restructuring}

A new stage of restructuring started in 2001 after Governmental resolution validation. The main goal of the stage is to provide stable work of the industry on the basis of competitive market development. The following measures are needed to succeed.

Development of a new legislative framework for the industry. The Parliament and the President enacted a new State Law "About Power Industry" in March 2003. The Law declared the market relationships in the industry as a main instrument for efficient and stable electricity supply. 
Two existing Laws, namely "State tariff regulation in the industry" and "State monopolies in Russian Federation", were changed. Additionally the Government issued several new Resolutions on pricing of electric and heat energy, the wholesale market rules and boundaries of pricing zones.

The new Laws and Governmental Resolutions form a power policy that provides broad guidelines for coming reforms and enact the legislation necessary for implementing this policy. It helps to provide a transparent regulatory framework and to establish a market encouraging efficiency improvement.

Restructuring local power utilities. Local power utilities are under restructuring now. They separate "non-profile" businesses and create new entities for power generation, distribution and supply. They introduce new systems for bookkeeping and financial planning.

Small and combined electricity and heat production plants formed local generating companies (GenCos). Later, the local GenCos were combined into 14 territorial GenCos to improve their maintenance and to make cheaper financial credits for development and reconstruction. Local distribution companies (DistCos) are to provide an open access to the electric networks for end customers. Later, the local DistCos were combined into 5 inter-regional DistCos.

Several supply (energy-sales) companies are under creation in each region.

They will compete for the end consumers by lowering the price of its services and by offering more profitable and convenient conditions of energy supply. One of the supply companies is Guaranteeing Supplier (GS). GS is a company, which continues the obligation to provide supply service to all customers on the GS's service territory who request such a service.

Competition can be introduced in the generation and supply spheres, but is not feasible for transmission, distribution, and system control businesses because these are the functions of natural monopolies.

Restructuring the holding RAO "UES of Russia". It is evident that RAO "UES of Russia" dominates the industry and must be promptly and substantially restructured to improve efficiency and attract necessary investment. The following steps were made in 2002. Some of them are expected in the nearest future.

The Federal Transmission Company (FTC) was created to operate, maintain and expand the national transmission network. Lines and substations with voltage $220 \mathrm{kV}$ and higher are combined under control of the new company. FTC will remain the sister company of JSC "UES of Russia" for two or three years. Later, 75\% of FTC's shares will belong to the State.

New company called "System Operator" (SO) was established to operate UES. SO is targeted to provide reliable electricity supply and non-discriminatory access to the networks. SO combined the Central Dispatching Board in Moscow and seven regional Dispatching Centers. Later the dispatching divisions of the local power utilities will join SO. The ownership of the State in the capital of SO is more than $75 \%$ from mid-2005. 
Administrator of the Trading System (ATS) was established as a non-profit entity for the wholesale market design and operation. ATS registers amounts of bilateral electricity trade, sets prices on the spot market for different buses of consumption, and supervises trading agreements and payments for electricity on the wholesale market.

Seven Wholesale Generating companies (GenCos) are designed and will be created with private property. The Wholesale GenCos have approximately equal installed capacities of 8.5-9 GW. Six of them will combine thermal power plants. One GenCo will consist of hydro power stations. Additionally, there is an independent GenCo consisting of 8 nuclear power plants. This company is supervised by the Ministry of Nuclear Energy and belongs to the State. Unbundled generating companies are established under dispersed ownership. Private investors are expected to bring financial resources to update running units and construct new ones.

Reforming the electricity markets. Significant developments are expected on the wholesale market. Two challenges will be available for electricity producers and customers. They may participate on the spot market or arrange bilateral forward contracts for electricity delivery. New companies such as the wholesale and local GenCos, local electricity suppliers, Federal Transmission Company and large end customers will participate on the wholesale market instead of vertically integrated utilities. System Operator will be responsible for safety and reliable operating conditions in UES.

A new pricing mechanism will be introduced in the wholesale market. Instead of blanket average prices a new market will introduce local marginal prices. The wholesale customers will pay at the margin what it costs to produce and supply electricity to them. On the one hand, it will encourage the power producers to improve the efficiency of production. On the other hand, it will result in price growth.

The spot market organization needs the development of sophisticated measurement system. Considering vast territory of the country this is a complicated technical problem.

Improvements in the State regulation. The State regulation of the industry should be concentrated on price regulation in the spheres of natural monopolies. On the wholesale market the focus of regulation is to prevent anticompetitive abuses and the market power exercises. On the retail markets regulation should be focused on balancing the interests of suppliers and customers. The prices in the natural monopoly spheres remain regulated including transmission tariffs, expenses of System Operator and ATS.

Prices in the competitive spheres are not regulated, but the Federal Energy Commission as the State Regulator can set price caps on the wholesale market. Also the State Regulator endorses the rules for customer's access to the networks and the procedures for tariff calculation. Local Energy Commissions regulate the tariffs for heat supply and electricity distribution as well.

Any cross subsidies between territories, groups of customers, different kinds of products (electricity and heat energy) and services should be eliminated step-by-step. 


\subsubsection{Investment Attraction into Russia's Power Industry}

The volumes of new equipment commissioned in the last decade have been extremely small. The average annual input of generating capacities in the years 1991-2005 was 0.6-1.5 GW per year, while in 1976-1985 construction of new capacities was 6-7 GW. In China this rate was $17,000 \mathrm{MW}$ annually during the last 15 years [8]. Financial injections into the industry were 5-6 times less than was required. This resulted in dangerous aging of generating and transmitting facilities $[7,8]$.

Therefore attraction of investments into Russia's electric power industry is a key problem. The solution to this problem will somewhat differ for privately owned generating companies and for network companies that are regulated natural monopolies.

Attraction of external investors is important for generation expansion and calls for:

- Essential increase in the investment attractiveness of GenCos by providing financial transparency, economic stability, predictability of management actions and other corporate measures;

- Considerable increase in the reliability of State guarantees to the investor by clear legislature, predictability and stability of State policies in electric power industry, etc.

- Effective system of investment risk insurance.

The above measures can considerably decrease financial risks for investors, which will not require high electricity tariffs to compensate for these risks.

At the same time the world experience shows that in a free market environment the shortterm purposes of power companies prevail over the long-term ones which, with time, may lead to an inadmissible drop in the reserves of generating capacities, formation of generation shortage and as a result growth of electricity tariffs $[7,8]$.

The new Law on the electric power industry envisages prompt and long-term measures not to allow such situations. The prompt measures imply introduction of price caps and then regulation on the markets in the event that there are no conditions for competition due to the shortage of generating capacities. A basic long-term measure is development of a State Program for generation expansion that would provide permanent availability of surplus capacities on the wholesale markets. This can be based, for example, on nuclear power industry that belongs entirely to the State. Distributed generation can also play and an important role here. The Program should form economic incentives for GenCos and external investors to invest the capital in construction of new power plants.

As to the regulated network companies, their development can mainly be provided by the investment component included in the tariffs for power transmission service. At the same time, due to insufficient transfer capability of the electric network, and the need of its essential increase to expand the conditions for electricity market operation, it may turn out to be necessary to attract additional investments both governmental and private. The volumes, conditions and mechanisms of attracting such additional investments require additional thorough scrutiny. 


\subsubsection{A Transition Period in the Restructuring Process}

A transition period has started since March 2003 after the new Federal laws were enacted. There are two sectors on the wholesale market during the transition period.

The first one is a competitive spot market with bids/offers submission on a per hour basis and with local marginal price setting. The other one is a fully regulated sector with "cost plus" principle of pricing for producers and average prices for customers within tariff zones.

Until 2006 the regulated sector worked with the single purchase agency. After January 2006 the sector was organized in the form of long-term bilateral contracts. The State Regulator will consider the prices of producers and define the set of suppliers for each wholesale customer. Prices within the bilateral contracts will be set for three or five years. Every customer will be able to dissolve the whole package of bilateral contracts once a year and join the competitive spot market.

Firstly each producer could sell up to $15 \%$ of its generation in the competitive sector. Year by year the share of sales in the competitive sector grows. In the end of transition period all electricity trade will be competitive. The Government defines duration of the transition period.

\subsubsection{Regional Problems of the Market Development}

The wholesale market of electricity in Russia has been established as the nationwide market. Nevertheless, the unity of the market exists only «dejure» [9]. The wholesale market is divided in fact into several large regions due to the high cost of electricity transmission and limitations in the transmission capabilities.

The European part of Russia including Ural, Siberia and the Russian Far East are three large regions. The structure of the economy, electricity consumption and climatic conditions in these regions are quite different. These circumstances bring additional troubles for using a nationwide model of the wholesale market. The Federal wholesale market in Russia should have distinctions at least in three large regions.

The European region of Russia has $72 \%$ of total installed capacity and $74 \%$ of total electricity consumption. Fossil fuel power plants in the region burn mainly natural gas. There are nuclear and peak (semi-peak) hydro power plants among producers. Generation is relatively equally spread over the territory. Transmission network is well developed and provides alternative ways for power supply. The European section of UES has the surplus generation and transmission reserves.

It seems reasonable to have the following model of the wholesale market:

a) the independent Administrator of the Trading System (ATS) in the region organizes and operates the day-ahead wholesale spot market. ATS works as a «flexible» entity arranging transactions as a brokerage system in the power exchange. The bilateral trade for a year and a quarter is permitted in addition to the centralized spot market;

b) large fossil-fired power plants and hydropower plants are combined into private generating companies. Nuclear power plants are combined into the State concern "Rosenergoatom", 
which plays as an independent producer on the wholesale market. Customers on the market are local supply companies and large power consumers;

c) ATS calculates the local marginal prices for electricity based on free bids/offers on the spot market. Contract partners define prices within the bilateral contract. The State Regulator sets tariffs for electricity transmission and the System Operator's services for a year. It sets the price caps for the spot market as well.

The Siberian region has $22 \%$ of the Russian generating capacity and $21 \%$ of total consumption. More than $50 \%$ of electricity is produced by large hydropower plants. These plants generate very cheap energy and have a strong influence on the economy and ecology of different territories. Almost $30 \%$ of total amount of electricity is generated in cities at cogeneration plants. Electricity generation at these plants greatly depends on heat consumption. Almost all fossil-fired power plants burn Siberian coals.

The transmission network has weak ties with the European sections of UES and is isolated from the Far-Eastern one. Power grid in the region is spread on a vast territory and has limitations on power flows in some cut sets. That is why it is difficult to provide an open access to the transmission network for all market participants.

Electricity generation and consumption in Siberia are subject to unstable natural impacts due to variations in river inflows and long droughty periods. The climate is severe with annual and seasonal temperature variations.

Considering specific conditions of the Siberian region the following market organization can be proposed as rational:

a) establishment of the Siberian branch of ATS with the same main principles of work as the ATS in the European part. Proportions between bilateral trade and spot market sales may differ from other sections of UES. Regional Dispatching Center, which is the sister-company of System Operator, supervises reliable operation of the power grid in Siberia;

b) electricity transactions should be provided among the market participants located in Siberia;

c) introduction of a technique for long-term generation scheduling and pricing for hydropower plants. The technique will take into account the availability of water in the reservoirs, ecological impacts and interests of water users;

d) introduction of a procedure for price setting on the spot market based on competitive prices of electricity and regulated prices of generating capacities. The procedure should reduce the "jump up" of the wholesale prices due transition from the average to the marginal principle of pricing;

The Far Eastern region has less than $10 \%$ of electricity generation and consumption. There are a few relatively large power plants combined with a weak and extended network. Electricity supply of many territories is separated from UES. There are no sufficient conditions yet for the effective competition among producers and suppliers. It seems reasonable to save the State regulation for electricity producers for the nearest future. Considering the importance of the Far East for the interests of Russia the power industry in this region needs special governmental support. 


\subsubsection{Expected Effects of the Market Reform}

New markets may result in:

1. Introduction of non-discriminatory relationships among market participants. It follows from unbundling the generation, transmission and supply businesses and from the new legislation enacting;

2. Removal of the cross subsidies among businesses, territories and customers. It will provide proper economic signals for electric power systems operation and development;

3. Encouragement of the electricity producers to reduce their production cost due to marginal pricing introduction;

4. Improvement in financial conditions for generation, transmission and distribution companies due to electricity price growth;

5. Attraction of domestic and external investments.

At the same time there can be some negative impacts including:

a. Increase in the wholesale and retail electricity prices due to introduction of marginal principle of price setting instead of average regulated approach;

b. Decrease in electricity supply reliability for the nearest future due to lack of experience in operation and control of new unbundled companies.

Thus, the following can be concluded:

1. The Russian power industry does need an improvement in efficiency of operation and new investment inflows. The industry and the Government see the main way out from current problems in restructuring of the holding "UES of Russia" and local power utilities. The market rules and market infrastructure should be improved for competition introduction.

2. The new State Law opens good perspectives for further progress in the restructuring process. The industry has entered a practical stage of restructuring. Power utilities are unbundling for separation of generation, transmission, and supply services. New market rules have been developed to improve the wholesale and retail markets.

3. Two challenges will be available for electricity producers and customers. They may participate in the spot market and arrange bilateral forward contracts for electricity delivery. There will be competitive and regulated sectors in the wholesale spot market during the transition period. Up to $15 \%$ of generated electricity is selling in the competitive sector now. Year by year the share of the competitive sector will increase.

4. The restructuring of the industry is accompanied by apprehension of significant increase in electricity prices and possible decrease in supply reliability. The restructuring process should be well prepared and staged over time. Any new reforming decisions have to be made after detail analysis of consequences and based on available potentialities. Different regions of the country may choose their own restructuring models and determine the terms and rates of restructuring.

5. Attraction of investments into Russia's power industry is a key problem. The new legislation in the power industry envisages prompt and long-term measures to develop generating facilities and electric networks. The long-term measure stipulates creation of the State Program of expansion planning that would provide permanent availability of surplus capacities in the wholesale markets. The Program should form economic incentives for GenCos and investors to invest the capital in power plants. Development of the market infrastructure can mainly be provided by the investment component in the tariffs for power transmission service. 
Russia has unique conditions for the competitive environment development. Its restructuring policy may be useful for large countries where the power industry is on the way of reforms.

\subsection{Power Industry Restructuring In China}

Restructuring and reform of the traditional integrated power industry has been started all over the world for more than 10 years. In various deregulated power systems, the market structures, the degree of privatization and the sequence of reform stages are different. China started the process of power industry restructuring since the late 1990s. In this section, the current situation of China power industry reform is introduced and the following issues will be focused on: market structure, electricity price policy, investment and planning, renewable energy in the new market.

\subsubsection{China Power Industry Structure and its Restructuring}

China has been experiencing significant economic growth since the 1980s. Electricity consumption increased more than three times due to the booming market and manufacture industry. At the end of 2004, the installed capacity in China has reached 440GW, and the annual generation has reached $2180 \mathrm{TWh}$. Both installed capacity and generation are ranked the second highest in the world. Within the $440 \mathrm{GW}$, the proportions of thermal units, hydro station, nuclear and wind power are $73.7 \%, 24.5 \%, 1.6 \%$ and $0.17 \%$, respectively [10].

\subsubsection{Power Industry Restructuring}

In February 2002, the State Department issued the Power Industry Structure Reformation Program. The program includes three main points: 1) Restructure state-owned generation assets, and establish several independent generation companies; 2) Restructure transmission assets, and establish two grid companies; 3) Establish State Electricity Regulatory Commission (SERC) to monitor and regulate the electricity markets.

On the 29th of December 2002, two grid companies, State Grid Company and South China Grid Company were established. The State Grid Company has five subsidiary regional grid companies. They are North China Regional Grid, North East China Regional Grid, Central China Regional Grid, East China Regional Grid and North West China Regional Grid. The geographical areas of the regional grids are shown in Figure 16.3.

On the same day, five independent generation companies were established. They are:

- China Huaneng Group,

- China Datang Corporation,

- China Huadian Corporation,

- China Guodian Corporation, and

- China Power Investment Corporation. 


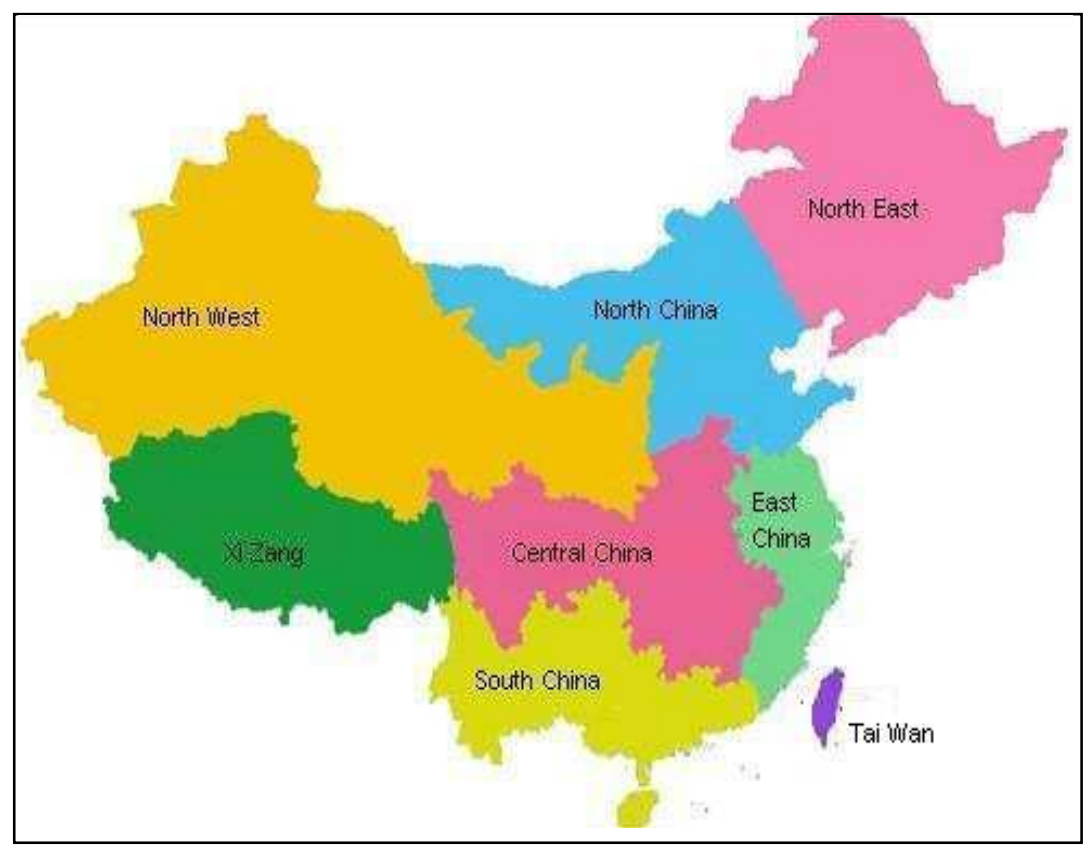

Figure 16.3. China regional grids

The installed capacities of the five-generation companies are given in Table 16.1. Each of the five-generation groups has a certain amount of share of any local market [11]. After the restructuring of generation assets, the State Grid and South China Grid own 24.5GW generation capacity, of which, 15.9GW capacity is used for frequency regulation and load following to ensure the reliable system operation [10].

The installed capacities owned directly by the two grid companies and all regional grid companies in 2004 are given in Table 16.2. The total generations of all grids in February 2005 are given in Table 16.3 [12].

\begin{tabular}{lc}
\hline \multicolumn{1}{c}{ Companies } & Capacity $(\mathrm{GW})$ \\
\hline China Huaneng Group & 40.98 \\
China Datang Co. & 4.95 \\
China Huadian Co. & 8.64 \\
China Guodian Co. & 29.30 \\
China Power Investment Co. & 27.96 \\
\hline
\end{tabular}

Table 16.1. Installed capacities of the five generation companies in 2002 


\begin{tabular}{ccccc}
\hline Power Grids & $\begin{array}{c}\text { Thermal } \\
\text { Capacity }(\mathrm{GW})\end{array}$ & $\begin{array}{c}\text { Hydro } \\
\text { Capacity }(\mathrm{GW})\end{array}$ & $\begin{array}{c}\text { Total Installed } \\
\text { Capacity }(\mathrm{GW})\end{array}$ \\
\hline \multirow{6}{*}{ State } & Own by State Grid & 9.8 & 2.1 & 7.7 \\
Grid & North China Grid & 77 & 74.5 & 2.5 \\
& North East Grid & 41.5 & 35.9 & 5.6 \\
& East China Grid & 78 & 64.4 & 11.6 \\
& Central China Grid & 65.4 & 41.9 & 23.5 \\
South China Grid & North West Grid & 27.1 & 18.8 & 8.3 \\
\hline
\end{tabular}

Table 16.2. Installed capacity in each grid company at the end of 2004

\begin{tabular}{lcc}
\hline \multicolumn{1}{c}{ Power Grids } & Generation (TWh) & Increase Rate (\%) \\
\hline North China Regional Grid & 32.6 & 5.67 \\
North East Regional Grid & 15.4 & 2.21 \\
East China Regional Grid & 30.3 & 1.62 \\
Central China Regional Grid & 22.9 & 6.45 \\
North West Regional Grid & 10.2 & 13.7 \\
South China Grid & 17.5 & 1.16 \\
\hline
\end{tabular}

Table 16.3. Generations of all grid companies in February of 2005

\subsubsection{Regional Electricity Markets}

The structure of China electricity market is a regional electricity market based on regional grids. The first regional market, North East electricity market, started generation auctions in January 2004. Four months later, East China regional market started its market operation [13]. The market participants of a regional electricity market are power system operation and exchange center, Grid Company, the five-generation companies and local provincial generation companies. The regional regulator commissions monitor and regulate the operation of regional markets. At the current stage, the system operation and exchange center is the single buyer of the market. The market settlement mode is Pay-as-bid. The Single buyer model has been used in many countries as a transition stage toward competitive market.

In the energy markets, generators provide long-term offers and short-term offers in the auction market. Long-term offers include annual transaction offers and monthly transaction offers. A Short-term day-ahead spot market will be established in the next stage of the regional markets.

Some hydro plants owned by the grid companies provide ancillary services, such as reserve, frequency regulation and voltage support. Some compensation mechanisms have been applied for the ancillary services provided by the units owned by the generation companies.

The mid-term goals of China regional electricity markets are: establish ancillary service markets; run day-ahead spot markets; consider unit emission criteria in the auction markets; start bilateral contract markets and generation right markets. The long-term goals 
are: open customer-side markets, establish financial markets, such as, futures, forward and option markets.

\subsubsection{Electricity Price Policy}

The electricity price policy plays an important role in China power industry reformation. In May 2005, the National Development and Reformation Commission (NDRC) issued three regulations about electricity prices, Generation Price Regulation, Transmission and Distribution Price Regulation, and Customer Electricity Price Regulation [14].

\subsubsection{Generation Price}

Generation price is composed by capacity price and energy price. Energy price represents the variable costs of a power plant. The price is obtained by competition through regional auction markets. It is the price for a certain amount of power during a time period. Generators can submit 3-segment offers or 5-segment offers depending on the market regulations. In some regional markets, the regional grid company provides a reference energy price for each provincial generation company.

Capacity price represents the fixed costs of a power plant. It can be calculated as following:

$$
\text { Capacity price }=\text { capacity payment } / \text { installed capacity } \text {. }
$$

Capacity price is determined by the installed capacity of the plant and the capacity payment, which is decided by the NDRC from time to time according to the power supply and demand of the time. The purpose of utilizing capacity price is to guarantee the basic benefits for power plants. The ratio of capacity price and energy price can reflect the degree of competition in a market. The higher percentage the energy price in a generation price, the higher competitive level the market is. In one of the regional markets, the capacity price vs. energy price can roughly be 1: [2 3].

Electricity price reformation in one of the core parts of power system deregulation. Price reformation will be accomplished gradually in a longer term in China. The current twopart generation price is a transition pricing mechanism towards completely competitive electricity market.

\subsubsection{Transmission and Distribution Price}

In the Transmission and Distribution Price Regulation issued by NDRC, the T\&D price is composed by transmission price, ancillary service price, and special service price. Transmission price covers the network expansion and maintenance costs. Ancillary service fee is paid for the regional grid companies for their provision of ancillary services, such as, reserve, frequency control, voltage control, black start, etc. Grid companies use gridowned units to provide such ancillary services. The special service prices are charged to market participants that require special services from the grid company. Such as, connect to the network; build a transmission line for a special project, etc. The government and NDRC decide the transmission and distribution prices. 


\subsubsection{Customer Price}

Electricity price for customer is regulated and decided by NDRC. Customer prices can be classified into three categories: residential customer price, industry customer price and agriculture customer price.

\subsubsection{Electricity Price Interlink with Coal Price}

Most areas of China have experienced a high increase of electricity consumption in 2003, and one third of the provinces are suffering power shortages [11]. In some areas, electricity demands are higher than power supplies. System operators sometimes have to shed load to balance the power demands. On the other hand, the fossil-fuel price goes up significantly at the time. Around $74 \%$ of installed capacities in China are fossil-fuel thermal plants. The high coal price limits the profits of power plants by a maximum extent.

In April 2005, NDRC announced a scheme to interlink electricity prices with coal prices. According to NDRC, customer side electricity prices can be adjusted with the change of coal prices. A few months later, the customer electricity prices in all provinces increased from 0.95 to 3.99 cents (Chinese Cent) per $\mathrm{kWh}$. The average electricity price of the whole country has increased 2.52 cents per $\mathrm{kWh}$ [15]. This price increase is around $5 \%$.

On the other hand, generation prices all over the country are adjusted with the increased coal price. The generation prices of all provincial power companies increased from 0.33 to 3.1 cents per kWh. Other Independent Power Producers (IPPs) followed provincial power companies and increased their generation prices to keep up with the coal price increase [16].

At the current stage of power system restructuring, government and NDRC are in a leading position regulating electricity prices. The government and NDRC determine both transmission and distribution price and customer side electricity price. Only generation prices can be partly decided by auction market.

\subsubsection{Renewable Energy Policy}

In China power system, coal-fired thermal power plants dominate the electric power generations (around 74\%). The generation costs and the electricity prices rely on coal prices to a certain extent. With the coal prices continuously going up in 2004 and 2005, the profits of most generation companies drop down. On the other hand, hydro generations are around $24 \%$ of the total generations. Renewable energy generation sources are not more than $1 \%$ of the total generations. The current renewable energy sources are mostly small-scale wind turbines. The slow development of renewable energy was due to the lack of market regulations and pricing mechanisms for high-cost renewable energy entering electricity markets.

In February 2005, the Renewable Energy Act was issued by NDRC. The Act indicates that the Chinese government encouraged renewable energy generation. The detailed regulations of the Act were enforced in January 2006. A proper renewable energy policy and a reasonable pricing mechanism would facilitate the development of renewable energy sources in China power system. 
The renewable energy generations currently used in China are mainly solar energy and wind energy. The solar energy generation production reached $230 \mathrm{MW}$ in 2005 . Some of the solar energy generations are installed at remote areas. In Shenzhen, a photovoltaic power station of $860 \mathrm{~kW}$ has been interconnected to the transmission grid. It is estimated that the total solar generation production could reach 500MW in 2010.

The total installed capacity of wind power in 2005 is 500MW. Besides this, the wind turbine capacity is going up at an annual increase rate of $40 \%$. The capacity is expected to reach $100 \mathrm{GW}$ in 2020 , which will be around $10 \%$ of the total installed capacity of that year. Wind power and solar energy generations are the potential new generation sources in the future China power industry.

One of the factors that limit development of renewable energy is the high production cost. The cost of renewable energy is much higher than that of the regular coal-fired generation. In China, the cost of small hydro generation is around 1.2 times of the cost of thermal generation; the cost of biomass generation is about 1.5 times, the cost of wind power is about 1.7 times, and the cost of photovoltaic generation is about 11-18 times [17]. The average generation price for traditional thermal sources is around $¥ 0.5 / \mathrm{kWh}$, the cost of wind power is usually around $¥ 0.8 / \mathrm{kWh}$ and the cost of solar energy could me more than $¥ 5 / \mathrm{kWh}$. Besides the high cost of renewable energy, the uncertainty of the renewable energy pricing mechanisms and the unclear renewable energy policy also raised the investment risk. Investors are hesitated to invest in renewable energy generation unless they can see the benefits.

The Renewable Energy Act and its regulations provide detailed rules about interconnecting renewable energy units to the grids and the detailed generation prices for various types of renewable energy.

In the new regulations, two parts compose renewable energy generation price: government regulating price plus market auction price. The wind power generation price decided by the government is expected to be the fossil-fuel generation price plus $¥ 0.25$ per $\mathrm{kWh}$. The generation prices for photovoltaic might be classified into two categories: $¥ 3.2 / \mathrm{kWh}$ for those located at open areas and $¥ 3.4 / \mathrm{kWh}$ for those located in buildings. The prices for other renewable energies, such as biomass energy, are also stated in the regulations [10]. The government-authorized renewable energy generation prices will insure the companies recover their generation costs and the return rate of investment.

To facilitate renewable energy generations, the government authorized some regulations as well as the regulating prices. In the Act, it has been explicitly stated that the future renewable energy policy will be a quota system. The grid companies must sign purchase contracts with renewable generation companies and buy all the contracted renewable energy generations in their grids as well as providing transmission services. On the customer side, the large customers are compulsory to pay for the shares of the renewable energy allocated to them. The future regulations might fix a required proportion of the renewable energy in a grid. On the other hand, some preferential policies will be issued to encourage generation companies developing renewable energy sources. For example, 
some perquisites might be provided for renewable energy, some funds are founded especially for renewable energy, providing tax reduction or low interest loan, etc.

In Shanghai, the government has started to enforce the regulations on special generation prices and purchase prices for Green Power. The residential customers are required to buy Green Power at least $120 \mathrm{kWh}$ per year.

\subsubsection{Investment and Planning}

The electricity consumption in China has been increasing in recent years. The total consumption in 2004 is $2.17 \mathrm{PWh}$, which is a $15 \%$ increase of 2003. In 2005, consumption increased by another $10 \%$ and reached $2.4 \mathrm{PWh}$. On the generation supply side, $50 \mathrm{GW}$ new generation capacity was installed in 2004, and 70GW new generation capacity was installed in 2005. However, it is still not easy for all investors to enter the market of generation investment. The five independent generation companies and local government owned generation companies play the dominant roles in generation investment, although the individual investors and overseas investors hope that they can hold a share in the investment market.

\subsubsection{Investment}

After the power industry restructuring, government regulates transmission and distribution. The generation side is deregulated, and independent power companies are able to participate in generation side markets. Each generation investment project is examined and discussed by the government before it is approved.

Currently, state-owned generation assets are around 90\%, and private investors and overseas investors own the other $10 \%$. Of the $90 \%$ state-owned assents, $35 \%$ is owned by the five-generation companies (including the 40GW approved in 2004), and the other $65 \%$ is owned by the local government generation companies [18].

The generation investors in China are mainly in five categories:

- The former state-owned five generation companies.

- Some other state-owned companies.

- Local government owned generation companies. They own around 55GW capacities in total.

- Overseas investors. They own 37GW in total.

- Other private investors.

In the new generation investment projects, the state-owned generation companies still occupy a large share. For example, the five-generation companies mostly invest in the 40GW generation capacities approved in 2004 .

\subsubsection{Overseas Investment}

At the end of the 1980s, electrical consumption demands increased dramatically. To attract oversea capital investments to the China generation market, the China government has provided a very high rate of return for overseas generation investments. The annual 
rate of return was as high as $15 \%-20 \%$. In some provinces, the local governments sign long-term contracts with investors.

The contracts guarantee that the generators can get fixed generation prices for a number of years. More than 30 overseas companies invested in power plants in China. In 1997, their total capacity reached $14.5 \%$ of the total installed capacity of the country. In 1999, the government started to abolish the fixed high rate of return. Some of the investors do not see the high profits any more and withdrawed their investment from the market. The overseas generation investment reduced from $14.5 \%$ of 1997 to $7.5 \%$ of 2002 .

\subsubsection{Power System Planning}

In the traditional integrated power system, planning is performed centrally. For some years, power system planning has been under a situation that generation planning always leads transmission planning.

After restructuring of the power industry, the integrated power system has been separated into some generation companies, and some grid companies. Who will perform power system planning is still not clear. The State Grid Company has the most possibility of being authorized by the government to perform transmission network planning for the whole country grid. Each regional grid company is responsible for its' own regional grid expansion and planning. Generation companies are responsible for generation expansions. Where and what size to invest new generations are decided by the government and the State Grid Company. Generation companies bid for building new generation capacities. The government and NDRC examine and approve all the expansion projects.

\subsubsection{Challenges}

There are some issues that need to be emphasized in development of the China power industry after system restructuring [19]:

- The structure of generation sources is not yet fully optimized. The proportion of fossil-fired generation sources is much higher compare to other clean renewable energy generation sources.

- The high proportion of generation relying on coal makes the electricity prices affected by coal prices significant.

- The transmission network expansion and planning are lagging the generation expansion. How to perform generation planning and transmission planning after unbundling generation and transmission is an emerging issue.

The challenges to the industry and government in the restructured power system come from several sides. From the investment side, efficient policies would facilitate the investment in renewable energy sources and in optimizing generation source structure. From the planning side, generation planning and transmission planning coordination is a big challenge for the unbundled system. An authorized body for power system planning might be a good option to solve the problem. From the development side, the current single-buyer regional electricity market is still in a transient stage towards the competitive electricity market. Electricity market models in all countries and areas are various. Find- 
ing the best electricity market model for the China power system will be one of the goals for the future China power industry.

\subsection{Restructuring of the Electric Power Industry and the Current State of the Power Market in Japan}

The restructuring plan for the Japanese electric utility industry has first focused on the major objective of lowering electricity rates, which are rather expensive by international standards, to levels comparable to those prevailing in foreign countries. However, the plan has called for achieving this objective through competition while also addressing public-interest issues such as environmental protection, with due consideration of the conditions specific to Japan, such as the nation's current heavy dependence on imported resources (Figure 16.4). Institutional reforms have therefore been pushed forward in accordance with the Basic Law on Energy Policy Making. A Japanese-style electricity deregulation model designed to secure fair competition while retaining the integrated power generation/transmission/distribution regime has been created with the existing electric power companies playing a central role in working to promote the public interest.

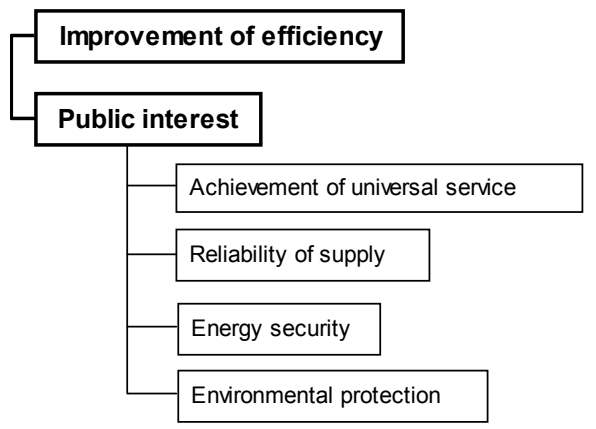

Figure 16.4. Basic principle of the restructuring

The Japanese electric power industry is being restructured in stages as discussed later. In the stage begun in April 2005, just over 60 percent of the retail electricity market was opened up, while basic mechanisms for the Japanese-style deregulation model, such as a neutral body and an electric power exchange, were put in place. Although it is still too early to judge the results of the restructuring, some appreciable benefits such as lower electricity rates have already been achieved. In fiscal 2007, discussion commenced on progressing toward complete retail deregulation. In order to provide inputs for this discussion, the efforts made so far to restructure the electric power industry were assessed.

This Section reviews the progress of restructuring and discusses the characteristics of the adopted Japanese-style electricity deregulation model. It then assesses and verifies the ongoing power industry-restructuring plan and reports on the results of the industry restructuring efforts $[20,21]$. 


\subsubsection{Progress in the Restructuring of the Japanese Electric Power Industry}

The restructuring plan for the Japanese electric power industry has made slow but steady progress through three broadly divided steps. The major milestones in these steps are as follows (Figure 16.5):

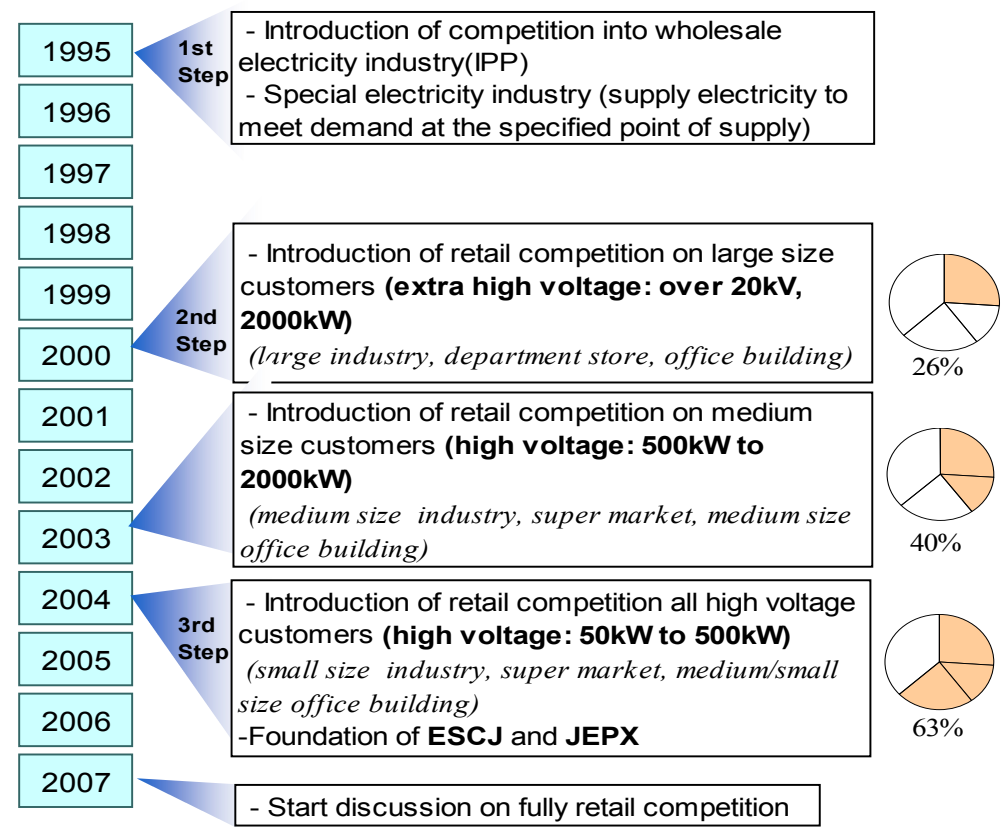

Figure 16.5. Steps of the restructuring

1st Step: 1995

- Liberalization of access to wholesale electricity industry (entry by IPPs)

- Introduction of a wholesale power supply bidding system

- Institutionalization of a retail electricity business at specified points of supply (Special electricity industry).

2nd Step: 2000

- Liberalization of retail electricity sales to extra high voltage customers (customers receiving electricity at $20 \mathrm{kV}$ and with contract power of 2,000 kW or more). Newcomers with power generating facilities are referred to as Power Producers and Suppliers (PPSs).

3rd Step: 2005

- Liberalization of retail electricity sales to high voltage customers (customers with contract power of $50 \mathrm{~kW}$ or more)

- Establishment of a neutral body, the Electric Power System Council of Japan (ESCJ)

- Establishment of the Japan Electric Power Exchange (JEPX)

- Elimination of pancake rates

- Revision of the balancing rule (the imbalance system). 
In Japan, in order to fully consider the characteristics of electricity and perform public welfare tasks, an electricity deregulation model designed to achieve structural reforms within the framework of electric power companies' integrated power generation and transmission system has been adopted. This is instead of the vertically unbundled electric utility model prevailing in the United States and European countries. The changes made in the third step are described in more detail as these represent the salient features of Japan's structural reforms.

\subsubsection{Outline of the Institutional Revisions Effective in $\mathbf{2 0 0 5}$}

Figure 16.6 outlines the institutional revisions made since April 2005. The main measures implemented include:

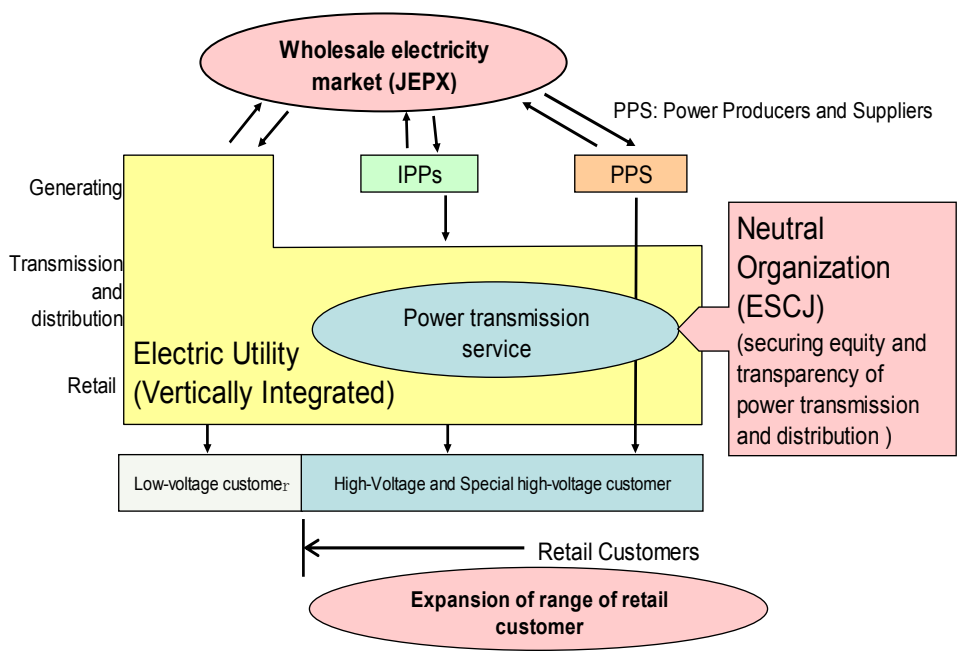

Figure 16.6. Institutional revisions made since April 2005.

1) Establishment of a neutral organization and the enforcement of activity regulations in order to secure fairness and transparency in the network sector within the integrated power generation/transmission framework

2) Creation of the Japan Electric Power Exchange

3) Expansion of retail electricity deregulation to cover all high voltage customers

4) Elimination of the pancake rate system in order to facilitate the use of power grids across the country.

\subsubsection{Neutral Agency}

The neutral agency is called the Electric Power System Council of Japan (ESCJ), and its main functions are:

1) Rule making for using power grids

2) Rule monitoring (settlement of disputes) 
3) Support for the operation of interconnected transmission lines (management of ATC, maintenance work coordination, and congestion management)

4) Provision of information about transmission systems.

As shown in Figure 16.7, the ESCJ is composed of a governing board and various expert committees, such as a rule-making committee and a rule monitoring committee under the control of a general meeting of members who are the general power utilities, PPSs, wholesale electricity suppliers and neutral parties, each having an equal voting right. A consultative board conveys the views of non-members to the Council.

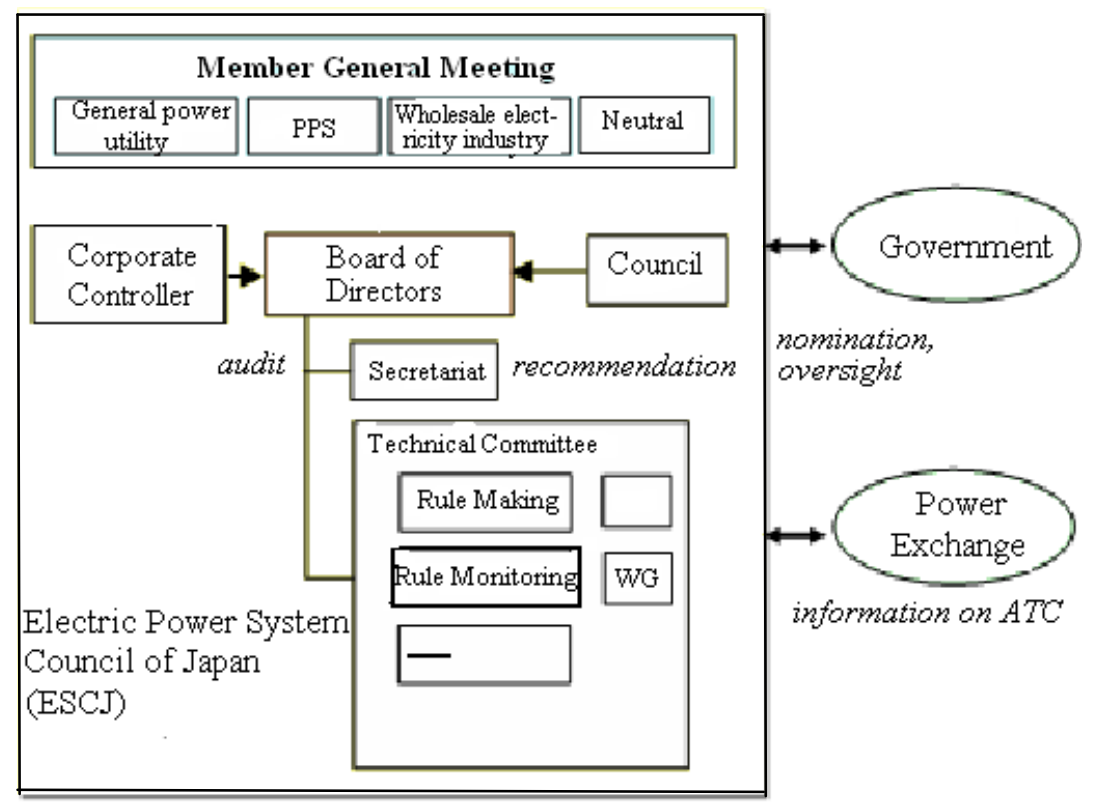

Figure 16.7. Structure of the ESCJ

\subsubsection{The Japan Electric Power Exchange}

The Japan Electric Power Exchange (JEPX) is a privately managed voluntary institution that was founded as Japan's first nationwide power exchange. The JEPX performs risk management functions, including the formation of a benchmark price, and the provision of selling and procurement means in the event of a mismatch of supply and demand.

Anyone who is capable of handling the generation and has assets worth 10 million yen or more can participate in the trading market. The JEPX deals in the following types of market.

1) Day-ahead market (spot deals):

Spot deals are deals for selling and buying electricity in units of 30 minutes to be used the next day and for 48 different commodities of electricity. Contracts are closed on the singleprice auction basis. 


\section{2) Forward market:}

Forward market deals sell and buy electricity for one year ahead from the following month in one-month units. Contracts for 24-hour delivery and for daytime delivery from 8 a.m. to 10 p.m. on weekdays are traded. Transactions are performed on a continuous session (priceoriented, time-oriented) basis.

\subsubsection{Assessment of Institutional Reforms}

A study on deregulating retail electricity for all customers started in fiscal 2007. The institutional reforms implemented so far are now being assessed and verified. The assessment looks at:

1) How macroeconomic policy objectives, such as enhanced efficiency, stable supply and environmental protection, have been achieved; and

2) What kind of results have the implications of individual institutional reforms, such as the elimination of pancake rates and the establishment of a neutral agency and an electric power exchange brought?

The results of the assessment were made available by the summer of 2006. This section summarizes the areas of assessment and the items assessed.

Regarding the macroeconomic policy objectives in 1) above, as shown in Table 16.4, the effects of the current institutional reforms on enhancement of the efficiency of electric power supply services, supply stability, and environmental protection is verified. Essential points in the assessment include the robustness of the electricity rate and trading market, capital spending, congestion of interconnected transmission lines, investment in the development of technologies, and investment without consideration of the environment.

On the other hand, the effects of individual institutional reforms are assessed in terms of the objectives mentioned in Table 16.5 . 


\begin{tabular}{|c|c|c|c|}
\hline Objectives & Issues & Areas of Assessment & Items of Assessment \\
\hline \multirow[t]{2}{*}{$\begin{array}{l}\text { Enhanced } \\
\text { efficien-cy } \\
\text { of electric } \\
\text { power } \\
\text { supply } \\
\text { service }\end{array}$} & $\begin{array}{l}\text { Retail elec- } \\
\text { tricity } \\
\text { market }\end{array}$ & $\begin{array}{l}\text { - Changes in electrici- } \\
\text { ty rates } \\
\text { - Factors contributing } \\
\text { to cost reductions and } \\
\text { rate cuts } \\
\text { - Initiatives other than } \\
\text { electricity rates }\end{array}$ & $\begin{array}{l}\text { 1) Electricity rates } \\
\text { - Changes in the levels of electricity } \\
\text { rates } \\
\text { - Quantitative analyses of the effects } \\
\text { of institutional reforms on electrici- } \\
\text { ty rates } \\
\text { 2) Factors other than electricity rates } \\
\text { - Efforts in terms of services } \\
\text { - Initiatives designed to strengthen } \\
\text { business bases, including technolo- } \\
\text { gical innovation and development } \\
\text { of overseas business operations } \\
\text { 3) Options for customers } \\
\text { - Number of suppliers and shares } \\
\text { - Customer satisfaction }\end{array}$ \\
\hline & $\begin{array}{l}\text { Wholesale } \\
\text { electricity } \\
\text { market }\end{array}$ & $\begin{array}{l}\text { - Robustness of the } \\
\text { power generation and } \\
\text { wholesale electricity } \\
\text { markets } \\
\text { - Performance of } \\
\text { JEPX's initial purpos- } \\
\text { es }\end{array}$ & $\begin{array}{l}\text { 1) Wholesale electricity market } \\
\text { - Trading volume by electric power } \\
\text { companies and PPSs, and prices } \\
\text { - Trade channels (cross trading with } \\
\text { JEPX, self-supply and purchase } \\
\text { from other companies, etc.) } \\
\text { - Correlation among wholesale elec- } \\
\text { tricity prices, generation costs and } \\
\text { retail prices } \\
\text { 2) JEPX } \\
\text { - Position of JEPX in the wholesale } \\
\text { market } \\
\text { - Trading volume and prices in spot } \\
\text { market and forward market, and } \\
\text { liquidity compared with bilateral } \\
\text { trading }\end{array}$ \\
\hline \multirow[t]{2}{*}{$\begin{array}{l}\text { Supply } \\
\text { Reliability }\end{array}$} & $\begin{array}{l}\text { Construc- } \\
\text { tion, main- } \\
\text { tenance } \\
\text { and re- } \\
\text { newal of } \\
\text { facilities }\end{array}$ & $\begin{array}{l}\text { - Facility investment } \\
\text { - Maintenance and } \\
\text { renewal of facilities } \\
\text { - Attainment of suita- } \\
\text { ble generating mix }\end{array}$ & $\begin{array}{l}\text { - Supply reliability } \\
\text { - Changes in the amount of facility } \\
\text { investment } \\
\text { - Facility maintenance levels and } \\
\text { measures for extension of life of } \\
\text { facilities } \\
\text { - A future power generation mix, } \\
\text { transmission line construction } \\
\text { plans, and electric power develop- } \\
\text { ment plans by PPSs, etc. }\end{array}$ \\
\hline & $\begin{array}{l}\text { Intercon- } \\
\text { nected } \\
\text { transmis- } \\
\text { sion line }\end{array}$ & $\begin{array}{l}\text { - Limitation of line } \\
\text { capacity }\end{array}$ & $\begin{array}{l}\text { - Construction of interconnected } \\
\text { lines } \\
\text { - Maintenance and operation of in- } \\
\text { terconnected lines }\end{array}$ \\
\hline
\end{tabular}

Table 16.4. Assessment of the Macroscopic Policy Objectives (continued on next page) 


\begin{tabular}{|c|c|c|c|}
\hline Objectives & Issues & Areas of Assessment & Items of Assessment \\
\hline \multirow[t]{3}{*}{$\begin{array}{l}\text { Supply } \\
\text { Reliability }\end{array}$} & $\begin{array}{l}\text { Load dispatching } \\
\text { control and sys- } \\
\text { tem management }\end{array}$ & $\begin{array}{l}\text { - Burden on load dis- } \\
\text { patchers } \\
\text { - Appropriateness of } \\
\text { ancillary services }\end{array}$ & $\begin{array}{l}\text { - Changes in electric power } \\
\text { companies' load dispatching } \\
\text { control and system man- } \\
\text { agement activities following } \\
\text { institutional reforms } \\
\text { - Harmony between protec- } \\
\text { tion systems such as special } \\
\text { protection schemes and } \\
\text { short-circuit relays and new- } \\
\text { comers' facilities } \\
\text { - Provision and operation of } \\
\text { ancillary services }\end{array}$ \\
\hline & $\begin{array}{l}\text { Safety and disas- } \\
\text { ter restoration }\end{array}$ & $\begin{array}{l}\text { - Changes in the func- } \\
\text { tions of safety and } \\
\text { disaster prevention } \\
\text { systems }\end{array}$ & $\begin{array}{l}\text { - Response to safety and dis- } \\
\text { aster restoration needs }\end{array}$ \\
\hline & $\begin{array}{l}\text { Technology de- } \\
\text { velopment and } \\
\text { succession of } \\
\text { skills }\end{array}$ & $\begin{array}{l}\text { - Necessity of devel- } \\
\text { opment of new tech- } \\
\text { nologies in the power } \\
\text { transmission and } \\
\text { distribution sector, } \\
\text { etc. }\end{array}$ & $\begin{array}{l}\text { - Implementation of technol- } \\
\text { ogy development projects in } \\
\text { response to institutional re- } \\
\text { forms }\end{array}$ \\
\hline \multirow[t]{3}{*}{$\begin{array}{l}\text { Environ- } \\
\text { mental } \\
\text { protection }\end{array}$} & $\begin{array}{l}\text { Choice of power } \\
\text { sources }\end{array}$ & $\begin{array}{l}\text { - Orientation toward } \\
\text { a generation mix at- } \\
\text { taching importance to } \\
\text { economic efficiency } \\
\text { only }\end{array}$ & $\begin{array}{l}\text { - Changes in the generation } \\
\text { mix and } \mathrm{CO} 2 \text { emissions in } \\
\text { the power sector }\end{array}$ \\
\hline & $\begin{array}{l}\text { Development of } \\
\text { environment- } \\
\text { related technolo- } \\
\text { gies }\end{array}$ & $\begin{array}{l}\text { - Efforts toward envi- } \\
\text { ronmental develop- } \\
\text { ment that have no } \\
\text { direct contribution to } \\
\text { profits }\end{array}$ & $\begin{array}{l}\text { - Investment in the devel- } \\
\text { opment of environment- } \\
\text { related technologies }\end{array}$ \\
\hline & $\begin{array}{l}\text { Interconnected } \\
\text { transmission line }\end{array}$ & $\begin{array}{l}\text { - Limitation of line } \\
\text { capacity }\end{array}$ & $\begin{array}{l}\text { - Construction of intercon- } \\
\text { nected lines } \\
\text { - Maintenance and operation } \\
\text { of interconnected lines }\end{array}$ \\
\hline
\end{tabular}

Table 16.4. Assessment of the Macroscopic Policy Objectives (continuation)

\subsubsection{Evaluation of Institutional Reforms in the Early Stage}

Institutional reforms are now being systematically evaluated from the above mentioned perspectives. This section evaluates the institutional reforms in their early stage based on currently available data. Note that some factors, such as electricity rates, can be accurately evaluated as the result of institutional reforms as sufficient time has passed since the early stage of the reforms, while it may be too early to evaluate other factors such as the robustness of transactions on the electric power exchange that were commenced in the third step of the reforms. 


\begin{tabular}{|c|c|c|}
\hline & Areas of Assessment & Items of Assessment \\
\hline $\begin{array}{l}\text { Wheeling } \\
\text { service sys- } \\
\text { tem }\end{array}$ & $\begin{array}{l}\text { - Elimination of pancake } \\
\text { rates and revitalization of } \\
\text { wide-area power transaction } \\
\text { - Functions of the new im- } \\
\text { balance charging system }\end{array}$ & $\begin{array}{l}\text { - Effects on wide-area transactions and } \\
\text { on JEPX trade } \\
\text { - Recovery of transmission line costs, an } \\
\text { appropriate cost reimbursement mechan- } \\
\text { ism, and restrictions on the siting of } \\
\text { power sources in remote places } \\
\text { - The incidence of imbalances and the } \\
\text { shouldering of charges }\end{array}$ \\
\hline $\begin{array}{l}\text { Activity regu- } \\
\text { lations }\end{array}$ & $\begin{array}{l}\text { - Securing of fairness and } \\
\text { transparency in the trans- } \\
\text { mission/distribution seg- } \\
\text { ment through activity regu- } \\
\text { lations }\end{array}$ & $\begin{array}{l}\text { (a) Information firewall } \\
\text { - Management of information related to } \\
\text { wheeling service, and formulation and } \\
\text { announcement of internal rules } \\
\text { (b) Prohibition of discriminatory treat- } \\
\text { ment } \\
\text { - A survey of cases of discriminatory } \\
\text { treatment in access to wheeling service } \\
\text { for specific power suppliers } \\
\text { (c) Prohibition of cross-subsidization } \\
\text { (keeping of different account books) } \\
\text { - Preparation and disclosure of docu- } \\
\text { ments needed to verify an income and } \\
\text { expenditure account statement and the } \\
\text { process of preparing the statement }\end{array}$ \\
\hline $\begin{array}{l}\text { Neutral } \\
\text { agency }\end{array}$ & $\begin{array}{l}\text {-Securing of fairness and } \\
\text { transparency in access to } \\
\text { power grids, construction of } \\
\text { facilities and disclosure of } \\
\text { information }\end{array}$ & $\begin{array}{l}\text { - Establishment of an organization and a } \\
\text { mechanism designed to achieve fairness, } \\
\text { transparency and neutrality } \\
\text { - Rule-making procedures securing fair- } \\
\text { ness, transparency and neutrality } \\
\text { - Consistency of load dispatching com- } \\
\text { munication and system information dis- } \\
\text { closure systems (OASIS) with the neutral } \\
\text { agency's rules } \\
\text { - Fairness and transparency in the } \\
\text { scheme for rule monitoring } \\
\text { - Current situation of rule monitoring } \\
\text { - Implementation of load dispatching } \\
\text { communications } \\
\text { - Appropriateness and security of the } \\
\text { information disclosure systems (OASIS) }\end{array}$ \\
\hline
\end{tabular}

Table 16.5. Assessment of Individual Institutional Reforms

\subsubsection{Electricity Rates}

The wide gap between electricity rates in Japan and in foreign countries, which triggered the structural reforms in the Japanese electric power industry, has narrowed compared with before restructuring of this industry was started, as shown in Figure 16.8. 


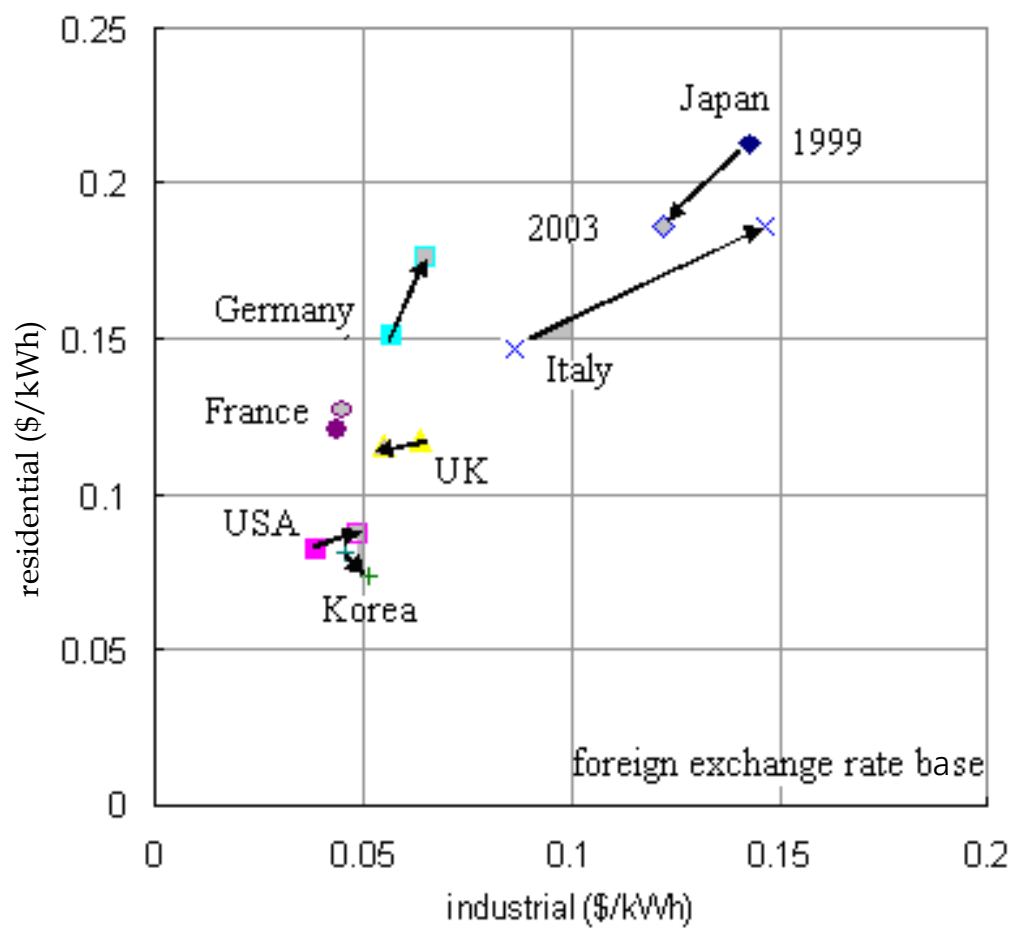

Figure 16.8. Comparison of electricity charge before and after the institutional reform

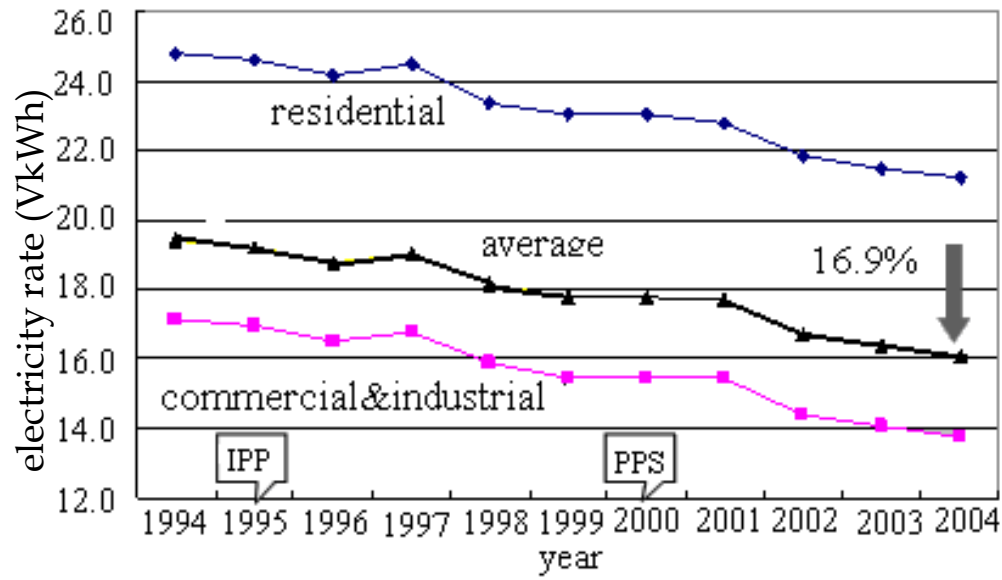

Figure 16.9. Changes in electricity rates over the past decade

Changes in electricity rates over the past decade are shown in Figure 16.9: electricity rates dropped by $1.8 \%$ annually on average from fiscal 1994 to fiscal 2004 and a simple comparison between electricity rates in fiscal 1994 and in fiscal 2004 shows a decline of approximate- 
ly $17 \%$. As the graph shows, residential charges, which are not liberalized, have declined to sufficiently lower levels. In the liberalized segment, a simple comparison between electricity rates in 2000 and in 2004 revealed a significant drop of nearly $26 \%$ in electricity rates for commercial customers.

\subsubsection{Situation of Newcomers}

A look at newcomers (PPSs) in the liberalized sector shows that although their share is still small at around 2\%, PPSs have been steadily increasing their power sales (Figure 16.10). PPSs' shares vary according to electric power companies. In Tokyo Electric Power Company's service area, where the utility meets an immense demand for power, newcomers hold a share of more than 5\%, whereas PPSs account for no more than $1 \%$ in the service areas of some local electric power companies.

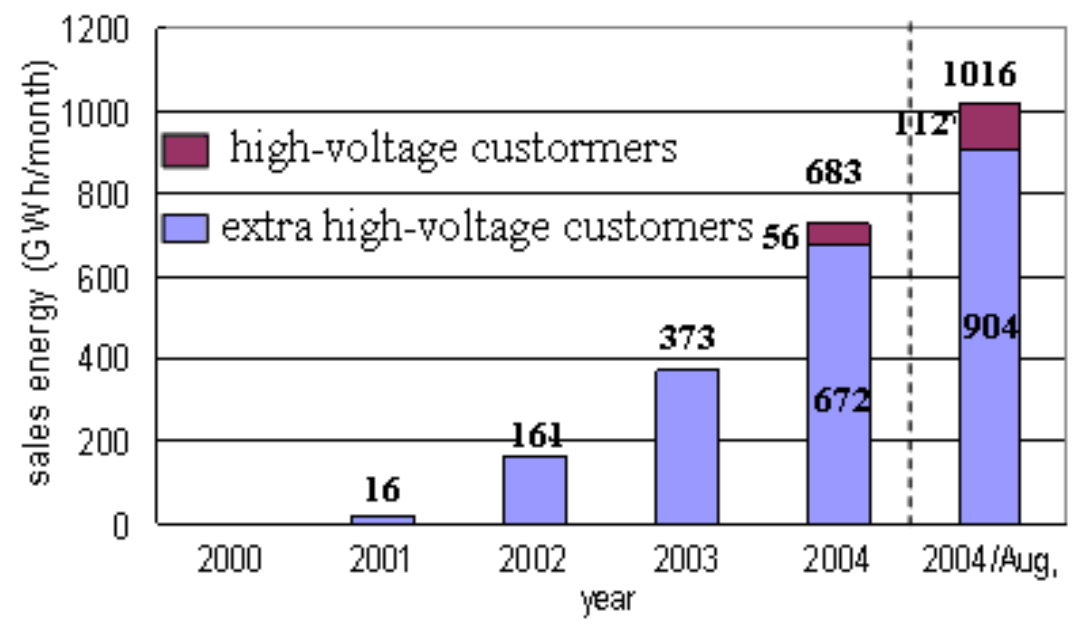

Figure 16.10. Share of power producers and suppliers (PPSs)

\subsubsection{The Japan Electric Power Exchange}

The Japan Electric Power Exchange is still immature as it was opened only in April 2005. As shown in Figure 16.11, over the five months following its opening, the exchange has had thin trading and prices are relatively high in summer, but subsequently transactions have increased gradually and prices have become steady. Reasons for this tendency include the emergence of relatively large sellers, a rise in oil prices, and the suspension of large power sources.

At the time of the exchange's opening, an outlook for trading volume was provided as shown in Figure 16.12. The actual volume of transactions already surpassed the estimate for the first year in mid November.

Challenges that the exchange must tackle in the years ahead include:

Measures to increase the trading volume: Increase in the number of exchange members, such as in-house power generation facility owners. 
Introduction of new commodities meeting needs: Introduction of short-term forward delivery contracts.

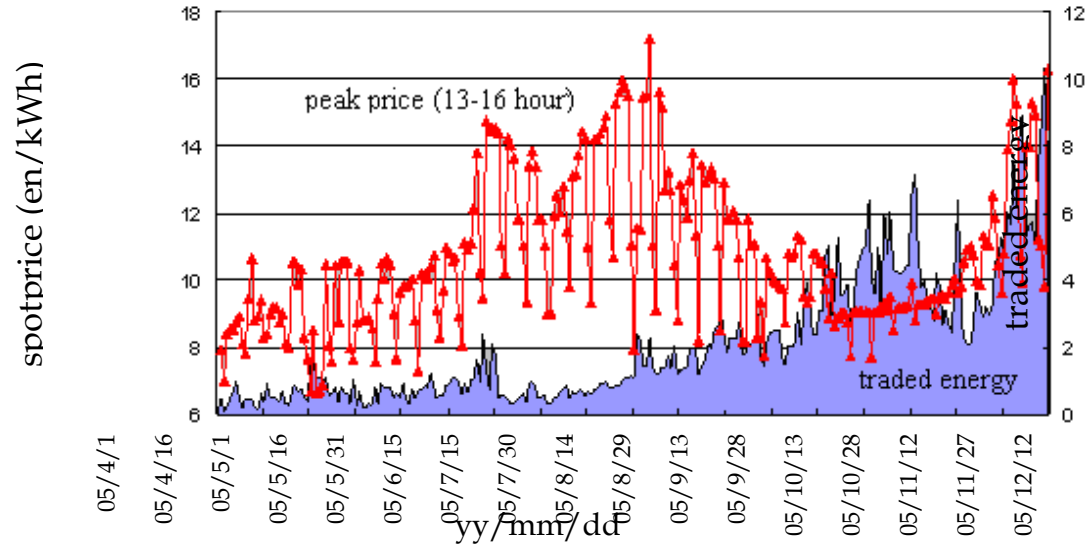

Figure 16.11. Price and traded energy in day-ahead market of JEPX

\subsubsection{ATC and Transmission Line Congestion}

Available transmission capacity (ATC) for the next ten years in Japan is shown in Figure 16.13 [22]. In Japan, due to the geographical conditions and historical background, interconnections between electric power companies are loosely connected and transmission congestion poses a problem in domestic interconnected lines. ATC is therefore presented for each interconnected line.

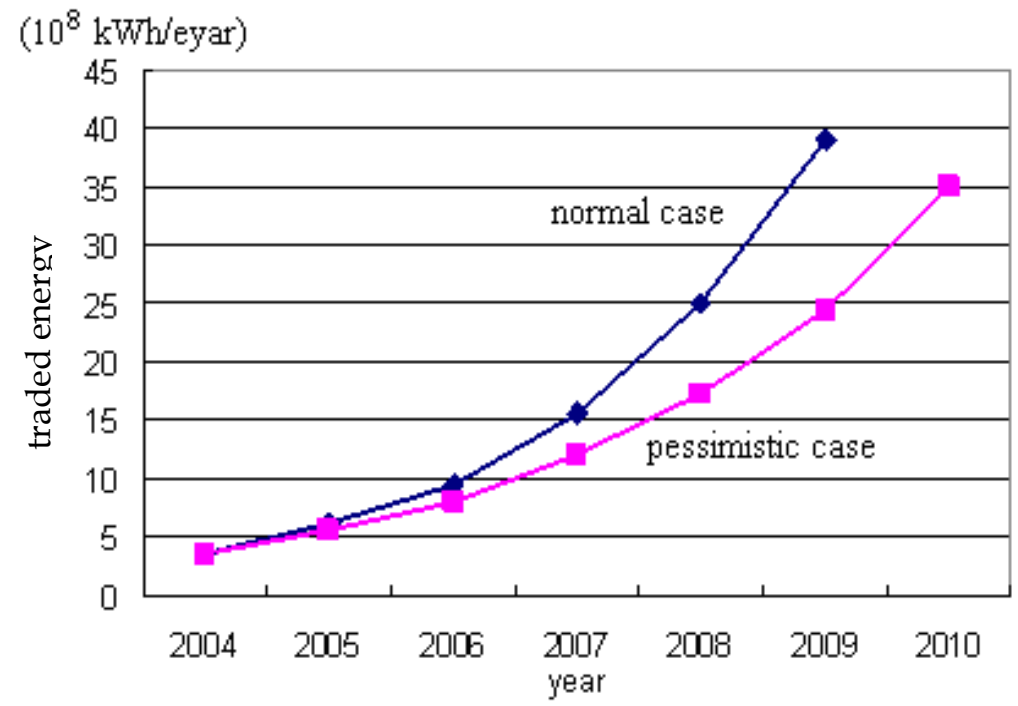

Figure 16.12. Prospect of trading volume (at the opening time of JEPX) 


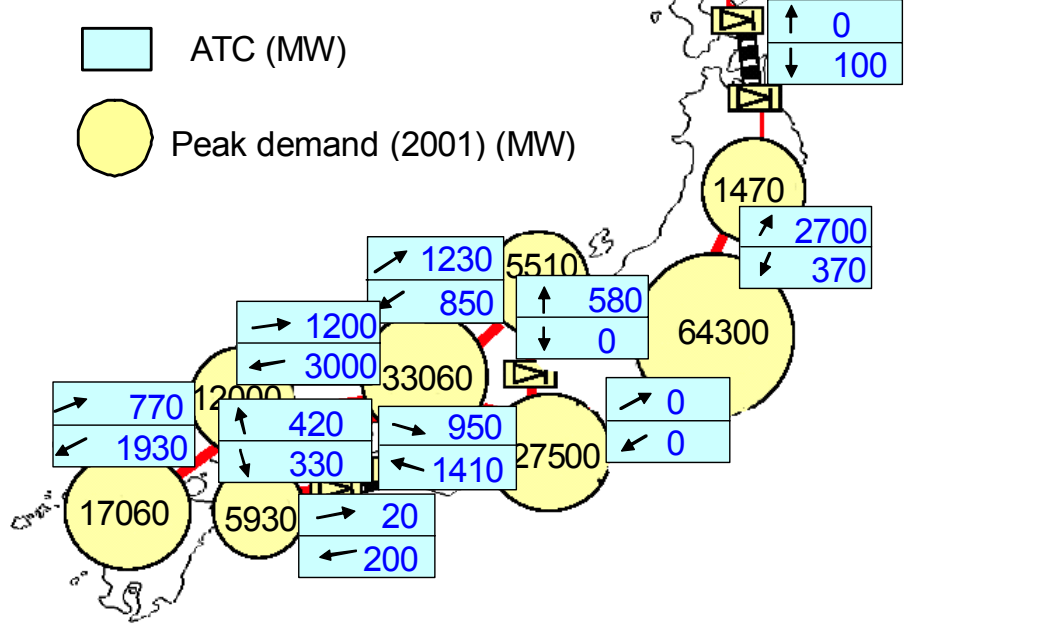

Figure 16.13. ATC of the interconnected line (from 2005 to 2014)

The frequency and duration of transmission line congestion are shown in Table 16.6. Congestion occurs several times a month. In September and October 2005, transmission congestion occurred due to a decrease in the counter power flow (a power flow in the opposite direction) resulting from the extended period of repairs on large power sources.

The ESCJ has undertaken a technical study on ways of managing interconnected transmission lines, including reinforcements.

\begin{tabular}{lcccc}
\hline \multirow{2}{*}{ Month } & \multicolumn{2}{c}{ Frequency } & \multicolumn{2}{c}{ Duration } \\
\cline { 2 - 5 } & Planned & Emergency & Planned & Emergency \\
\hline April & 0 & 1 & 0 & $10.82 \mathrm{~h}$ \\
May & 1 & 0 & $130 \mathrm{~h}$ & 0 \\
June & 4 & 2 & $90 \mathrm{~h}$ & $26.5 \mathrm{~h}$ \\
July & 3 & 3 & $123.5 \mathrm{~h}$ & $56.97 \mathrm{~h}$ \\
August & 1 & 1 & $80 \mathrm{~h}$ & $744 \mathrm{~h}$ \\
September & 20 & 2 & $660 \mathrm{~h}$ & $257 \mathrm{~h}$ \\
October & 31 & 0 & $824 \mathrm{~h}$ & 0 \\
November & 3 & 1 & $123.5 \mathrm{~h}$ & $39.6 \mathrm{~h}$ \\
\hline
\end{tabular}

Table 16.6. Congestion of Interconnected Lines (2005) 


\subsubsection{Adequacy of Generation Capacity}

One of the ESCJ's functions is to assess reliability of the power system. An assessment of the adequacy of generation capacity is given in Table 16.7. The adequacy of power sources is expected to be maintained at an appropriate level for the next ten years or so.

\begin{tabular}{lcc}
\hline & \multicolumn{2}{c}{ Demand/Supply Balance } \\
\cline { 2 - 3 } & 2009 (August) & 2014 (August) \\
\hline Peak demand & 18,200 & 19,246 \\
Planned capacity & 19,838 & 21,268 \\
Reserve ratio & 1.09 & 1.11 \\
\hline
\end{tabular}

Table 16.7. Prospect of Generation Adequacy

\subsubsection{Capital Investment by Electric Power Companies}

Capital investment by electric power companies has fallen sharply over the past several years as shown in Figure 16.14. This decline has occurred partly because demand growth has slowed down as shown in the Figure and partly because electric power companies have virtually completed their bulk power transmission systems through investments made over the years. In fact, reductions in capital spending have released financial resources that have allowed the electric utilities to lower electricity rates.

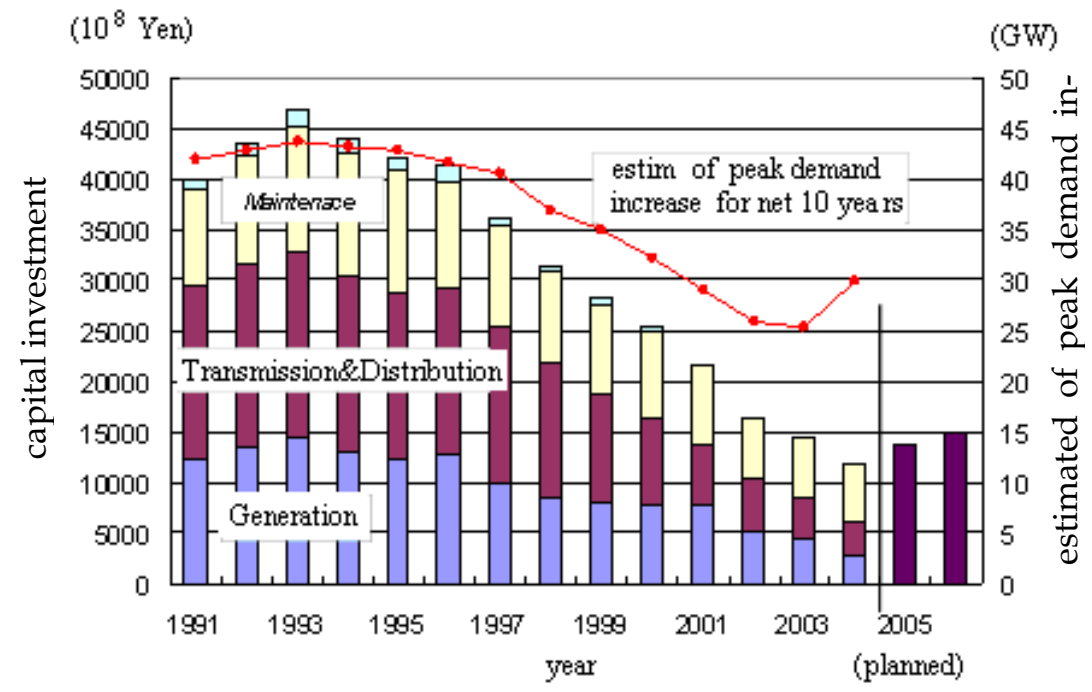

Figure 16.14. Trend of capital investment in utilities

The population of Japan began to decline in 2005, much earlier than expected, and so electric power demand cannot be expected to increase significantly in future. Still, the facilities that were constructed during the growth period will have to be renewed by around 2010. How the facilities should be managed within the context of electricity deregulation is an important question that remains to be answered. 
Thus, this Section has outlined the institutional reforms in the Japanese electric power industry and an assessment of the reforms already made. The structural reform of the Japanese electric power industry is characterized by a step-by-step approach as well as by reforms being implemented within the framework of electric power companies' vertically integrated power generation and transmission structure. Although it is still premature to draw conclusions about the results of the structural reforms, electricity rates have dropped and the differential between electricity rates at home and abroad has narrowed considerably. A national-level assessment of the institutional reforms was made and the results were produced in the summer of 2006. Based on these results, discussion has commenced in order to establish a Japanese-style electricity liberalization system.

\subsection{Pricing for Transmission Services in Korean Electricity Market}

In Korea, the trend of heavier real power flows into densely populated load centers from several vast power plants in remote locations will continue or become profound, leading to their national-interest in transmission bottlenecks during some periods of the year. The first step toward increasing the role of market forces in managing transmission system operations is to develop the role of location price signals to direct the actions of market participants toward outcomes that improve operations when congestion occurs on the bulk power grid. In this overall perspective, we need to thoroughly investigate how best it would be to send an adequately accurate location price signal with the congestion costs incorporated into the transmission pricing rule when the electricity market is not unduly maintained. This Section attempts to make a supportive and self-explanatory proposal that it could fit the Korean Cost-Based Pool (CBP) that satisfactorily sharpens the location price signal.

\subsubsection{General Characteristics}

\subsubsection{The Evolution of Competition in Korean Electricity Industry}

It used to be assumed that electricity generation, transmission, distribution and supply enjoyed significant vertical economies that would be lost if the functions were placed under the control of different companies. Such long-held belief made it possible that the Korea Electric Power Corporation (KEPCO) had monopoly power - supported by legal protection. Since the 1997 financial crisis, economic policy in Korea has aimed to remove barriers to trade and competition. Network industries like electricity and natural gas, which were historically sheltered from competition and operated within national or regional boundaries, have experienced radical change as a consequence. National pressure to liberalize electricity markets reflected the perceived benefits of introducing market forces into the electricity industry previously viewed as a natural monopoly with substantial vertical economies. In the meantime, the generation sector was split into six subsidiaries that will be privatized. Still, the KEPCO is being engaged in monopolistic business activities of the transmission and distribution systems alike. In an attempt to help mitigate potential negative prospects about which the hasty reform drive could bring, a new transitional electricity market, dubbed 'Cost-Based Pool (CBP)', was set up in 2001. 


\subsubsection{The Distinctive Feature of CBP}

The characteristics of the Korean CBP market can be briefly summarized as follows:

- The Korea Electric Power Corporation (KEPCO) is the single purchaser. Exceptionally, large consumers (above 50MVA) and district electricity businesses can either buy electricity directly from the Pool or KEPCO.

- The generators added at peak load are given the short-term marginal price (SMP) and the capacity payment, $7.17 \mathrm{won} / \mathrm{kW}$ as the fixed cost, while the base-load power plants receive both the base-load marginal price (BLMP) and the capacity payment, 21.49 won $/ \mathrm{kW}$ as the fixed cost. When the CBP was first designed, greater portions of the windfall profits from the high SMP for each generation company were envisaged because of the shortage of base generation capacity. Thus, the so-called BLMP was adopted to evade the excessive revenues of the base-load generators.

- As such, there is no location price signal. If the generators inevitably change their output due to the congestion, they have been paid the uplift to make up for their generation cost.

- The generation cost is a priori known by the committee's actual test. Individual generation companies offer their available capacities alone, not prices. Then the Korea Power Exchange (KPX) performs economic dispatch based on the generation fuel costs.

- Indeed, the transmission price seems to be nominal in that it is published every year but not really applied to the market participants. In the CBP, the KEPCO collects the electricity price from the customers on a regulated tariff and provides the variable costs (SMP and BLMP) plus the capacity payment for the generation companies.

Originally, the futuristic model, namely Two Way Bidding Pool (TWBP) in which the marketclearing price would be determined from the bids of customers and the offers of generation companies in the unconstrained dispatch, was supposed to commence in 2004 in order to overcome the shortcomings of the current CBP. However, the government halted it and accordingly the $\mathrm{CBP}$ is expected to continue for the time being.

\subsubsection{Pricing for Transmission Services under the Cost-Based Pool}

Now, the main drawback in the CBP is an essential absence of the location price signal. Though either nodal pricing that recognizes different prices at every location or zonal pricing that creates administrative aggregations to reallocate costs is a nearly dominant answer to the prospective price signal in energy markets $[23,24]$, it would be really time-consuming to rectify the current uniform pricing regime and, at the same time, redesign the market in terms of future network infrastructure costs. The access charge such as license plate or postage-stamp method is widely accepted to meet revenue expectations. In some European electricity markets, the power tracing method has been introduced for full cost recovery and location price signal [25].

\subsubsection{The Basic Structure of Pricing for Transmission Services}

In general, the overall equipments of transmission system are grouped into connection assets, common and location components, respectively. The pricing for transmission services in the CBP mainly consists of the access charge and the transmission usage charge as seen in Figure 16.15. 


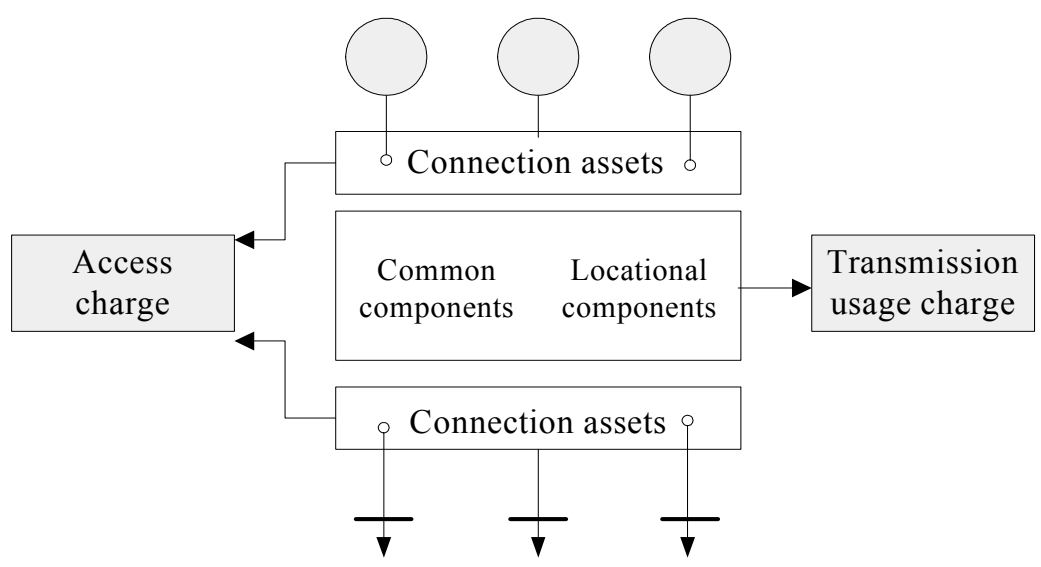

Figure 16.15. The basic structure of Korean transmission pricing

- Access charge: All the market participants who would likely use the transmission system should pay the charge for the connection assets that directly interconnect them with the substation. As is well known, a 'deep' basis is better rather than a 'shallow' basis in case of the access charge. From a practical standpoint, the CBP comes to have a clear preference for a "shallow" basis since it is a relatively good tool for elaborating the stringent criteria.

- Transmission usage charge: The electricity passing the connection assets is transmitted from generators to loads through the core of transmission system. Two components, i.e. the location and the common service components, are included hereof. In principle, the common component is made up of facilities related to the reactive power, non-operational land holdings, communication equipment, whereas the location component encompasses transmission lines and circuit breakers, etc. In the CBP of Korea, postage-stamp rate method is traditionally used for the common component, while the power tracing method associated with the location component is poised to give a location price signal to the participants. In Figure 16.16 , the transmission charges in the CBP are represented for better understanding.

\subsubsection{Power Tracing Method}

The gist of the tracing method is to evaluate the contribution of transmission users to transmission usage of location components. This method may be employed to determine which generators are supplying corresponding loads, how much use each load is making of specific transmission lines and what are the annual costs of individual network elements to be recovered.

Especially, the cost of substation with which several branches are connected is actually divided into each line. In this method, more detailed load flow analysis of the system and its operation at the peak time are usually required to allocate the estimated annual costs of network elements to all the participants who use them. In an early stage, the fault current based power tracing method in the Victoria pool was scrutinized, but at this time, the methodology set forth by Felix Wu is in popular use [26]. 


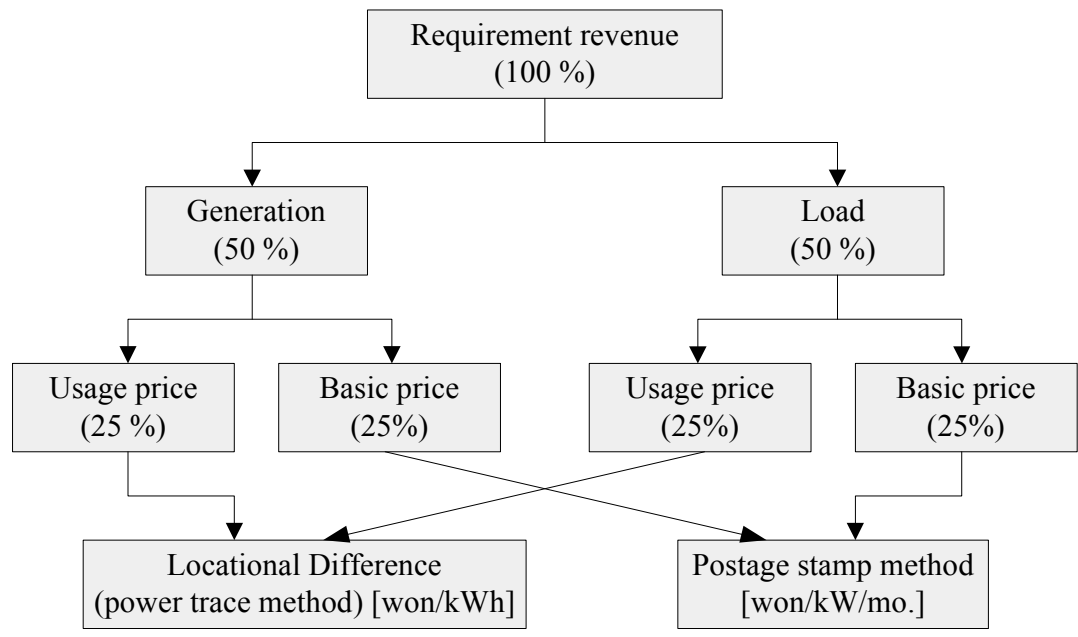

Figure 16.16. Illustration of transmission charges in the CBP

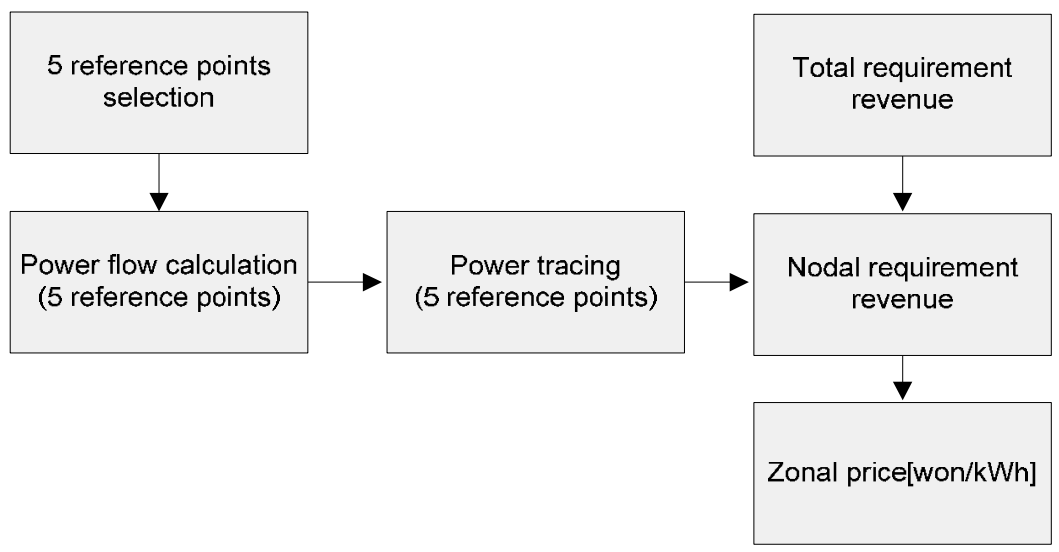

Figure 16.17. Procedure of usage price calculation

A natural implementation of the proposed algorithm is described in the following procedures (see Figure 16.17):

1) Choose 5 reference points when each load reaches $100,90,80,70$ and $60 \%$ of peak load.

2) The power tracing method is applied for 5-averaged load-demand and generation level at buses, allowing for a whole set of 5 reference points.

3) The cost of each transmission line is calculated using equipment replacement cost which deals with what it will cost to replace the piece of equipment in the future and then converts the future cost into today's pricing.

4) All 5-transmission prices as to each bus are created from a pair of the averaged demand and supply at the respective reference points. A weighted average of 5 transmission prices against the elapsed time is equal to the final transmission price at each bus. 
5) The zonal price, or a weighted average of the node price against the corresponding loaddemand within the same zone, is derived.

\subsubsection{Case Study}

Data from Korea electric power system is used to calculate transmission prices. Figure 16.18 is a schematic showing locations of major generation and transmission facilities in the Korea electric power system. From the geographical point of view, the system can be characterized in the following [27]

- Island system

- Concentration of load demand in the metropolitan region

- Location of major generation plants in non-metropolitan regions

- Environmental concerns and restrictions on regional transmission siting.

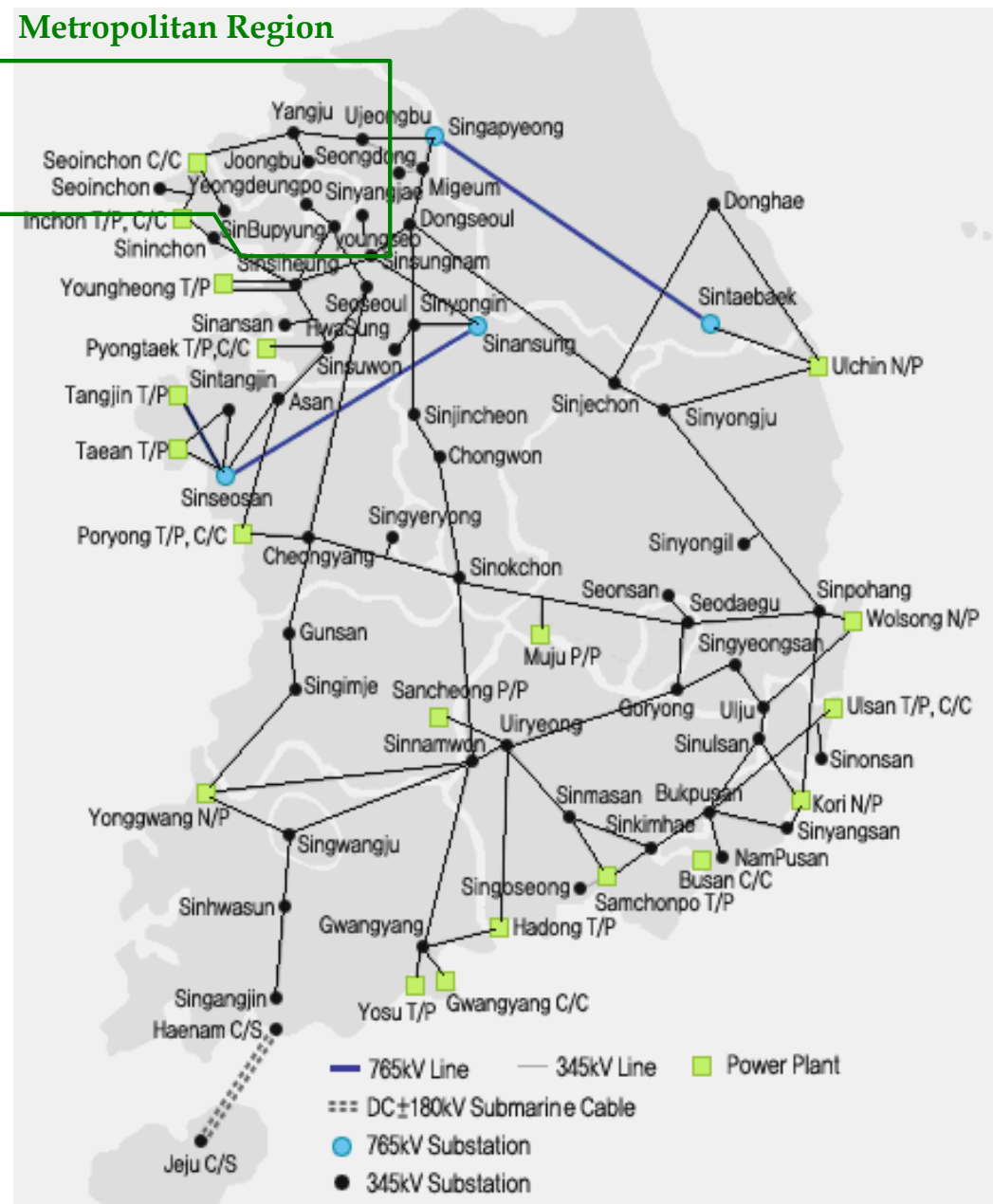

Figure 16.18. Schematic of major transmission facilities in Korean electric power system 
The transmission price calculation algorithm used in NETA and Ireland is applied to the Korea electric power system for comparison with CBP method. In the results of simulations, it shows that the methods of NETA and Ireland provide stronger location signal than the CBP's. In Figure 16.19, the left side of the horizontal axis indicates the nodes of metropolitan region and the right side indicates the nodes of non-metropolitan region. While there are negative prices in the metropolitan region for the methods of NETA and Ireland, there are all positive prices in the CBP's method.

Even though providing location price signals is an important role of pricing transmission services, it is undesirable that these methods should be applied to the Korean pool model. The reasons are as follows:

- The energy markets of NETA and Ireland is run by contracts without location price signals.

- Most of the electric power markets include capacity market or capacity payment. In CBP, capacity payment is paid to all generators who submit capacity offers. For example, lower efficient generators in the metropolitan region make an additional profit on negative transmission price.

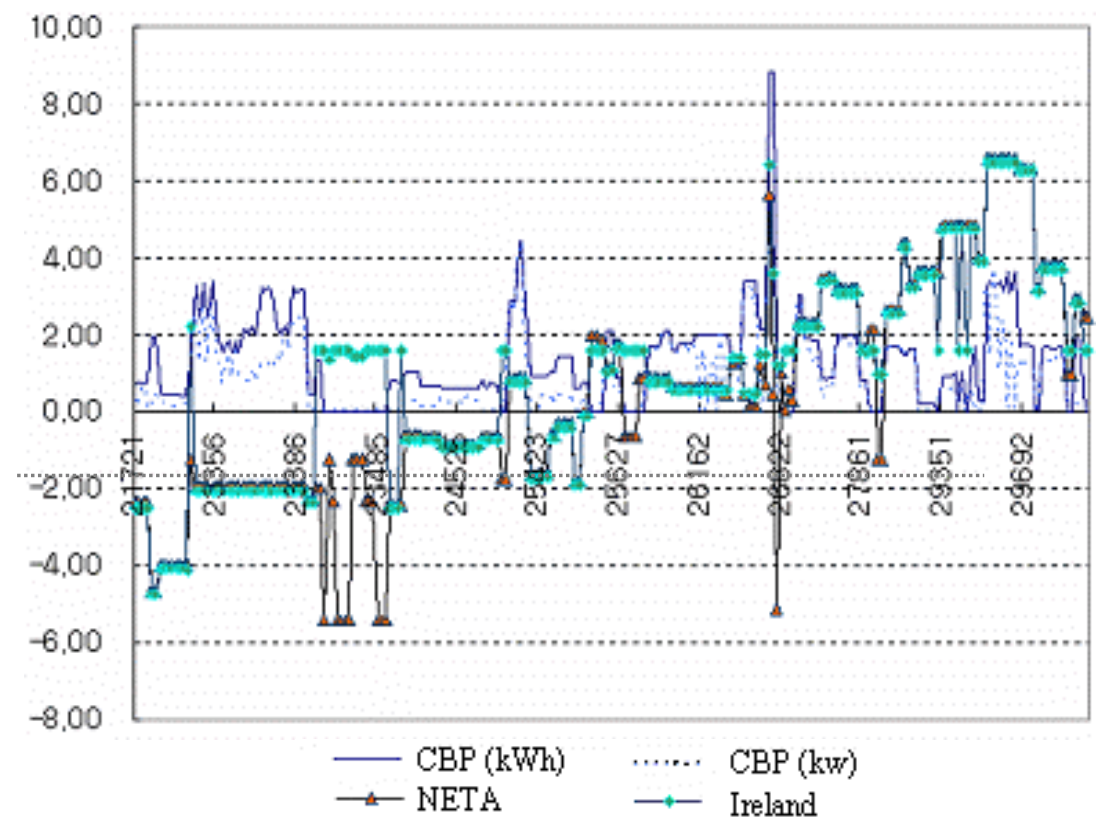

Figure 16.19. Comparison with transmission price calculation algorithms

\subsubsection{The Challenges from Pricing Transmission Services in the Cost-Based Pool}

\subsubsection{Access Charge}

- Though it is clearly stated that the already established generation companies in the $\mathrm{CBP}$ should take the responsibility for the access charges, they do not pay for these 
charges as it is. Conversely, a group of independent power producers with the power plants in course of construction is installing the connection assets as long as their budget allows. That is, new entrants are being outright discriminated from the old ones in the CBP model.

- It is even difficult for the existing generation companies to be imposed on the access charge in the CBP environment. That is why the market should reward those companies with the SMP, CP and infinitesimal reserve-related charge which are earmarked according to the generation fuel costs and installed generation capacity, and hence they can afford no extra payments for access charges, let alone the transmission prices. This critical defect is fairly associated with not only the access charges but also the transmission pricing in itself.

- For some generation companies, they are linked with the common components via the transmission line whose voltage might be as high as $765 \mathrm{kV}$. Those companies are facing a heavy burden with the enforcement of the capacity investments of the past.

- Today and increasingly in the future, some parts of connection lines may be constructed across quite long-distance routes so as to be utilized for the common components.

\subsubsection{Transmission Usage Charge}

In relation to the transmission usage charge, the following questions can arise:

- Further work will be needed since the allocation rules, with rating the shares of the generation companies and load entities or common and location components at fiftyfifty, are totally unconvincing forceful standards.

- In fact, the extent or systematic methodology of yielding location price signal should be discussed in a meticulous way and it should ultimately have a bearing on the energy market. But neither the CBP energy market nor capacity price provides location price signals between two areas. Therefore the pricing for transmission services to provide different location price signals between two areas is necessary.

- The appropriateness or usefulness of the power tracing method will be analyzed in detail.

The states of power systems are subject to change, relying solely on the planned maintenance overhauls for generating units, new entry of power plants and the configuration of the infrastructure. Nonetheless, the ongoing method does not capture the changes of conditions in power systems, with the transmission price through the year fixed at a single value. It needs to be identified how much impact each of the factors have on the transmission price so that the transmission pricing should be able to enhance fairness and efficiency.

Thus, in the face of much complication, the Korean government has been committed to putting the final touches on the public services in the electricity industry, reiterating its willingness to go ahead with the policy. The fruit of these incessant efforts has proved bitter as yet. In these staggering surroundings, it is a brilliant future task to see the inherent limitations of the current Cost-Based Pool and find fundamental solutions without delay. To be sure, it will be allowed with the nation's consent if there are attractive alternatives to the aforementioned tantalizing problems. Apparently, the transmission pricing should be a reasonable economic indicator used by the market to make decisions on resource allocation, system expansion and reinforcement [28]. 


\subsection{Economic Convergence Points of Russian, CIS and Asian Power Markets}

The convergence of Asian power markets crosses political and geographical boundaries. This Section provides an analysis of the technical and economic commonalities involved. The two primary goals of power sector reforms have been liberalization and the establishment of a competitive power market.

This Section discusses the fundamentals of cooperation, and the primary goals of power sector reforms. The main reform priorities and primary strategic areas are discussed in the context of the developing power market in Russia. Also the Section makes the point that despite the large geographical area, and economic disparity of Asian countries, there are commonalities to be considered in power sector reform. Each country should create a reform methodology in a national and regional conceptualization.

It is explained that there are five common steps on which this can be based. Additionally, when determining the correct model to apply to an economy to bring about the desired efficiencies, it is important to consider 13 transitional issues.

\subsubsection{Economic Analysis of Russian and CIS Power Sector Interconnections and Markets}

The Commonwealth of Independent States ${ }^{*}$ (CIS) power sector has been characterized by cooperation, liberalization, privatization, investment, and cross border integration of electricity markets [29]. The fundamentals of cooperation have been stated in the CIS agreement entitled "On coordination of interstate relations in the field of electricity of the Commonwealth of Independent States" signed in February 1992. Arising from this agreement, cooperation has been implemented in the areas of structural reforms, power system integration, legislation and price liberalization. This is in response to serious power sector problems experienced by CIS countries in financial, technical, operational, and investment areas. As a group, the CIS countries faced additional crises because of the 12 members, only four; Azerbaijan, Kazakhstan, Russia, and Turkmenistan have enough fuel and energy resources to cover internal demand.

The primary goals of power sector reforms in the CIS have been liberalization and the establishment of a competitive power market. This has been conceived, since 1996, as a complex process, based upon relevant technological, structural and legislative foundations [29]. Many of the CIS countries have phased-in the process of power sector reforms. These reforms have followed previous global experiences by de-integrating vertically integrated monopolies into distinct distribution, transmission, and generation companies. This has established the foundational single-buyer model of market reform, in preparation for more liberalization. The single-buyer model was introduced in developing countries in the 1990s.

\footnotetext{
* The CIS is composed of: Armenia, Azerbaijan, Belarus, Georgia, Kazakhstan, Kyrgyzstan, Moldova, Russia, Tajikistan, Turkmenistan, Ukraine and Uzbekistan. In October, 2000, the heads of five countries (Belarus, Kazakhstan, Kyrgyzstan, Russia, and Tajikistan) signed an agreement on the creation of the Eurasian Economic Community. Armenia, Moldova and Ukraine have observer status under EAEC. In October, 2005, Uzbekistan agreed to join this organization. In September 2003, four countries (Belarus, Kazakhstan, Russia and Ukraine) signed an agreement on the Formation of CES (Common Economic Space).
} 
It provides exclusive rights for a single transmission and dispatch company to purchase all electricity from generators and then sell it to distributors [30].

The single-buyer model became popular in the CIS countries and elsewhere because of technical, economic, and institutional reasons. These include:

- Balancing of electricity input and output is facilitated by a single dispatch method in real-time.

- The "contract path" problem is avoided.

- The single-buyer model is usually responsive to the sector Ministry in the areas of generation capacity investment and state-owned company's financial affairs. The most influential stakeholders favor this.

- Price regulation is simplified, maintaining a unified wholesale price.

- The single-buyer model is favored by politicians who do not agree with a complete withdrawal of the state from wholesale electricity trading.

There is evidence, however, that it is more efficacious to adopt a market model that has multiple buyers formed immediately after unbundling, in areas such as the CIS. The singlebuyer model is criticized because it tends to place generation capacity expansion decisions in government officials' hands, which do not assume the financial consequences. This model also makes the state ultimately responsible for poor power purchase agreements that cannot be honored. This is regularly part of the contract agreement. This model also does not respond well to reductions in electricity demand. Wholesale electricity prices will rise in response to demand reduction because of fixed capacity charges, which must be applied to a reduced volume of electricity purchases. Another drawback is the under-development of cross-border power trade. This is because the state-owned single-buyer has very little profit motive. This can cause long-term problems when a neighboring country or region develops a more liberalized power market model. Incentives for distributors to collect payments from customers are also reduced. Again, politically unpopular decisions are difficult for a stateowned entity. This is important because in the single-buyer model, delinquent payments from distributors are assumed by the aggregated cash proceeds of the single-buyer. Paying and non-paying distributors are treated basically the same, weakening the resolve of distributors to enhance the collection of payments. Another political intervention in this model has been experienced in the Ukraine and Poland. In these countries, groups have lobbied on behalf of coal miners to provide special treatment for coal-fired power plants. Interestingly, because of the political advantages of the single-buyer model, some governments have significantly delayed the next "phase" of fully liberalized markets [30].

The CIS has experienced advances in the privatization of the power sector. For example, Armenia, Azerbaijan, Georgia, Kazakhstan, Moldova and the Ukraine have either contracted the management of electric companies, or sold generation companies and distribution electric grids. Modernization through the construction of energy facilities has been facilitated by the creation of a legal basis. This has attracted direct investments in improvement projects from internal and external sources. For example, Armenia, Azerbaijan, Georgia, Kyrgyzstan, Tajikistan and Uzbekistan have received investments in projects ranging from hydro power plants, steam gas turbine units to electricity grid restoration [29]. 
There has been ongoing integration, and re-integration of the CIS power systems. For example, in June 2000, the power system connections of Russia and Kazakhstan were restored. Since the autumn of 2001, 11 of the 12 CIS countries have re-synchronized their power systems as an interconnected power system of the Commonwealth of Independent States (IPSCIS) [29]. Additionally, the CIS is involved with power exchanges and trade with the neighboring countries of Afghanistan, China, Finland, Hungary, Iran, Norway, Poland, and Slovakia. The CIS power authorities believe that cross-border synchronization is beneficial because it places better use of existing generation capacity, provides emergency assistance options, and harmonizes standards in the areas of safety, ecology, and technology.

As part of an economic analysis of Eastern Europe and CIS transitional development from centralized planning to free market forces, a framework is used to evaluate the impact of infrastructure upgrades [31]. Research has indicated that "The potential for developing competitive markets in transition economies had been inhibited by the inadequacy of both the institutional and physical infrastructure inherited from the socialist era." Although the following are general recommendations for transition economies, the following economic contributions of marketenabling infrastructure can be applied to the power sector:

- Market Selection: By increasing market competition, infrastructure investments that reduce transaction costs reduce the market share of higher-cost firms. This raises the average production efficiency of the economy.

- Infrastructure Investments: If these investments increase product market competition, incentives for firms should change to help reduce their costs by engaging in a restructuring plan.

- Increasing Market Share: If lower cost firms enter the market, they have probably been attracted by an infrastructure that lowers transaction costs (European Bank, 2000).

Therefore, each investment project in the CIS power sector can be evaluated in terms of the contributions of direct market selection, restructuring and entry.

The primary problem with the power sector in Russia, in the context of the CIS, has been inadequate investment [32]. Reasons for this are found historically, primarily being a lack of investment in generation capacity, and increased industrial activity and subsequent higher demand. A main goal has been to attract internal and external large-scale investments to the potentially competitive elements of the power sector. Although Russia has formed a plan, crafted in 2001, to eventually liberalize wholesale and retail electricity tariffs and to privatize segments of the sector, other contiguous CIS members have taken a lead in reformation. Kazakhstan was a reform leader by unbundling transmission, distribution and generation. Most generation and distribution assets have been privatized, but transmission networks are still owned by the government. In April 1999, the government of Kazakhstan approved a program to develop the electric power sector, with a view to 2030 [33]. The main priorities are:

- To have economic and population self-reliance in electric power, and to have energy independence as part of national security.

- To create competitive resources for electric power export to supply energy markets of contiguous and third countries.

- To develop a competitive electric power market on the basis of electric power transport and distribution networks accessible for generators and a system to control power flow. 
The primary strategic areas are:

- To create a Kazakhstan unified energy system (UES).

- To restore the synchronous network with Russia, and other energy networks of central Asia.

- To further develop an open and competitive market for electric power.

- To commission new generation capacity to offset power imports.

Assuming these priorities, it is useful to view Kazakhstan as a precursor to significant, similar changes in Russia. In 1990, the electricity shortage in Kazakhstan reached a level of 17.3 billion kWh [33]. This shortage was made up by power imported from Kyrgyzstan, Russia and Uzbekistan. In 1996, the state generation and power grid monopoly was the object of reform, with the aim to create a competitive power market. That year, the government initiated a program to privatize and restructure the power sector formalized by Decision No. 663 of May 1996. Because of this decision, large generators were sold to investors, and a grid company was created to own and maintain the high voltage grid assets, including voltage levels of 1150, 500 and $220 \mathrm{kV}$. Additional decisions (1188 of September, 1996 and 1193 of July, 1997) provided a model for Kazakhstan to follow for the creation of an electricity market. Designed for competition, the single electricity market would have two levels, wholesale and retail. The trade of electricity would be based upon fixed date bilateral purchases and transactions, and agreements on grid capacity. The competitive model would be brought about by pro-active changes in the electricity sector:

Restructuring to create an effective, competitive market based on forwards contracts under the supervisory control of a centralized dispatch.

A testing period for competitive market principles and enhanced quality indicators, especially regarding current frequency.

The creation of a pool of reserves - comprising a market of electricity reserves.

As of 2003, the wholesale power market is functioning on the basis of bilateral contracts. The electricity exchange for day in advance power purchases was established in February 2002. The total volume of sales at the exchange is considered to be $7 \%$ to $10 \%$ of the total supply of electricity for Kazakhstan [34].

Hirschhausen and Waelde [35] have posited that an economic transition period from socialistic to capitalistic markets, especially in energy, no longer exists. Interestingly, the authors make the critical point that experience with emulating institutional models has shown that they often work very differently for the emulator than the emulated. Utilizing an institutional interpretation of energy sector reform in the CIS, the authors contend that the transition from socialistic to market based economies has led to diverse outcomes. These differing outcomes are based primarily upon the pre-existing formal and informal institutions that dominate the particular country. The CIS countries have looked to Western market economies as models for the restructuring of their power sectors. Two diametric cases that have been studied are the UK and French approach. The authors qualify this statement by suggesting that there is no theoretically or empirically discernable best practice to structure and 
regulate the global energy sector. The CIS, including Russia, however, have overwhelmingly chosen the UK (British) approach which has been reproduced in Australia, Canada, New Zealand, Scandinavia, and several U.S. states. This approach has been marked by very direct privatization, corporatization, and competition. The French system, in contrast, has essentially maintained integrated monopolies protected from competition. Despite the similarities found in the French and formerly Soviet approaches, linked by a dominating public service obligation and a close relationship between management and politics, the French system has not been the model of choice for the CIS. The initial elements of the approaches found in most CIS countries have been to:

- Identify appropriate reform models from international experiences,

- Attempt to re-produce those models in an effective way domestically,

- Allow the domestic model to emerge and evolve with conceptualized principles [35].

Interestingly, after surveying international examples, some countries such as Russia and the Ukraine have crafted early proposals that have included additional competitive elements. This enthusiasm for the UK approach can be tied to what is perceived as superior wealth generation, technological innovation and swiftness of economic response to the needs of the market. Possibly most importantly to consider, Hirschhausen and Waelde [35] indicate that the AC connection of Poland and other east European countries to the West European grid was an external impetus to modernization. This is an important recognition of the relation between the physical connections of electricity grids of distinct systems, and the subsequent need to reform such areas as security, technical requirements, quality and communication. Indeed, this is demonstrated by the relationship of technical and economic needs of the Japanese power grid interconnection (PGI) considered with Eurasia. Arakawa [36] suggests that a major issue concerning Japan's PGI is the "eventual interconnection of the Japanese power system with the Eurasian mainland [which] will be achieved with restructuring of Japan's electric power market to be freely competitive. In addition, the relationship between Japan and Russia must be improved to a point that the neighboring nations will be able to cooperate, for example, in mutual development of Siberian natural resources. Apart from political and economic concerns, no major technical difficulties in PGI are anticipated".

Projects such as the potential Japanese-Eurasian interconnection can be financed through three main approaches, (1) public ownership, (2) public-private partnership, and (3) private ownership. Though not the primary focus of this Section, more rigorous analyses of potential Asian interconnections should be carried out before assuming the existence of financial, capacity, or reserve capacity incentives. For instance, if the potential interconnections are between two monopolies, then analyses can be carried out using bilateral monopoly trade theory. This would be particularly useful with a monophony - monopoly power market scenario. However, in this scenario, the Nash equilibrium theorem cannot be used because the asymmetry found between distinct systems discounts the determination of a unique price. 


\subsubsection{Convergence of Asian Power Markets}

Asia-Pacific Economic Cooperation*, (APEC), created in 1989 to continue to stimulate regional economic growth, has remained a consensus-based entity, without binding agreements [37]. APEC, although a non-treaty based organization, is having a significant impact on the reform of the Russian economy, including the Russian power sector. The primary purposes of APEC have been to encourage economic growth, trade, investment and cooperation in the AsiaPacific region. APEC is a 21-member organization, each called a Member Economy, representing $47 \%$ of global trade. The APEC Member Economies include the Russian Federation as an integral participant. Particular themes can be found in APEC interests, including:

- Reduction of tariffs.

- Efficient domestic economies.

- Increased exports.

Other APEC activities include policy creation and economic cooperation to facilitate the exchange of products across regional borders [37].

Established, and ongoing studies of the APEC economic area electricity supply industry have indicated that reform in the developed economy members has been designed to improve efficiency in the sector. In contrast, the developing economy members have sought reform because of partial access to electricity supply, low infrastructure investment, uneconomic pricing of electricity, and inability to manage high demand growth [38]. The progress of microeconomic reform of the APEC electricity sector has been steady across both developed and developing member economies. Despite the large geographical area, and economic disparity of member economies, an APEC energy-working group has concluded that there are commonalities to be considered in electric sector reform:

- Governments remain responsible for the outcome of reform, even after industry restructuring takes place.

- If governments cannot demonstrate the success of reform programs, there may be political consequences.

- Reform needs to be conceptualized to each member economy based on needs, circumstances, and resources.

- Despite advances in a competitive electric market, electric security and stability of the entire system must always take precedence.

- Restructuring has been defined as a "break-up" of generation and supply, which are contestable, and mostly non-competitive elements of transmission and distribution.

- The introduction of a competitive electricity market will create high risk for consumers if supply is unreliable, or becomes unreliable. High levels of competition are not appropriate for developing economies in the early stages of electric sector reform.

- If the impetus is to keep the electricity market at a marginally competitive level, other aspects of the system can be made more competitive. The separation of the transmission system and the creation of a competitive system to acquire primary and secondary energy are examples.

\footnotetext{
* APEC's 21 Member Economies are: Australia, Brunei Darussalam, Canada, Chile, People's Republic of China, (Hong Kong, China), Indonesia, Japan, Republic of Korea, Malaysia, Mexico, New Zealand, Papua New Guinea, Peru, The Republic of the Philippines, The Russian Federation, Singapore, Chinese Taipei, Thailand, United States of America and Viet Nam.
} 
- The historical emergence of competitive electricity markets has arisen "naturally" from trade between distinct power systems via sub-national and national power system interconnections.

- Under pricing of electricity removes much of the incentive to invest in infrastructure.

- There is no "reform standard". This being the case, it is important to create an objective setting, monitoring and measuring system to manage reform.

- Highly valuable empirical reform experience can be lost. It is important to retain talented experience for ongoing institution building [38].

Importantly, it can be maintained that each member economy should create a reform methodology in a regional and national conceptualization. However, there are five common steps that this can be based upon:

- Create national policy objectives.

- Identify reform risks.

- Assume and implement reform strategies that are realistic.

- Project-manage the reforms.

- Create an institutional unit to consistently monitor the progress of reforms.

Interestingly, the research methodology used by the APEC energy working group was composed of a literature review, interviews of reform participants in APEC economies, crosssectional assessments of the current status of reform, and applications of practical experience in case studies of developed and developing economies in APEC. Overall reform of the electricity sector has been divided into eight primary sections:

- Policy objectives

- Management

- Structure

- Framework for law and regulation

- Mechanisms for wholesale market

- Transmission and distribution

- Retail tariffs

- Privatization [39].

By utilizing mixed research methodologies to provide analyses, each of these eight sections has strategic principles designed to provide common points of reference for reform, and to also provide the basis for a conceptualized approach. Interestingly, Principle 35, under Wholesale Market Mechanisms, states: "The establishment of a competitive wholesale market should only be considered in the context of overall market structure and design" [39]. Wholesale market mechanisms should be able to interface with regulatory frameworks, transmission and distribution planning, and access. This should account for the need to provide cost effective supply from generation to the distribution connecting points. Competitive wholesale market mechanisms are integral to overall power system reform planning and implementation. The primary aim of power system reform should be to improve economic efficiency. This can be divided into three areas:

Productive efficiency, which is the relationship between production input and output, and the implementation of best practice concepts. 
Allocated efficiency, which are the way resources are utilized, in the light of appropriate signals for investment and consumption.

Dynamic efficiency, which is the extent that innovation and productivity increases are encouraged over a specific duration [39].

Critically, when determining the correct model to apply to an economy to bring about the desired efficiencies, it is important to consider transitional issues. These transitional issues include:

\section{Ownership}

If the current model of the power sector is a state-owned monopoly, full privatization should be delayed until it can be determined that the new companies will be viable, and after new markets have been tested.

\section{Incumbents}

If competition is introduced, incumbent utilities are under an obligation to reduce operating costs, and to develop new strategies and new markets to supply power to. The restructuring of the industry creates new risks for incumbent utilities. This includes the areas of finance, regulation and politics. As an example, generators can have competition amongst local power suppliers. Additionally, as the electricity grid becomes more interconnected, with more room for capacity, interstate and international generators then add to the competitive marketplace.

\section{Stranded Costs}

Stranded costs are the historical costs, mainly through generation plant construction, that may not be recoverable in the new prices charged in a competitive market. Generally, there are four types of stranded costs:

1) New generating plants could out-compete old plants, necessitating the decommissioning of older plants.

2) Competition can provide lower cost, long-term fuel or power purchasing contracts. Utilities bound to uneconomic contracts have higher input costs, and consequently a loss in earnings, making recovery difficult.

3) Utilities that have been obligated to invest in "regulatory assets" can find that the regulatory regime can change under a competitive environment, reducing their protective "extended payment plans" by deregulated, lower prices.

4) Other public policy programs such as Demand Side Management (DSM) programs can be stranded, as their cost recovery will become impossible in a deregulated system [39].

Although full recovery of stranded costs are rare, most experts in the field agree that governments should pay utilities for stranded costs, on a case by case basis, based upon specific attributes of the utilities in question.

\section{Security of Supply}

Two primary aspects of security of supply must be considered when planning and implementing a transition to competitive markets. They are the securing of long duration sources of generation fuels and the reliability of the power system. 


\section{Investment}

It has been found that competition in generation can reduce incentives to invest, and lower operating costs. In building the reform of the power system, it is important to create a system for signaling the need for generation capacity and power grid improvement.

\section{Reliability}

Reliability, by definition, is moving from strictly technical reliability to economic reliability. Economic reliability is composed of a contractual arrangement between generators, distributors, and consumers, reflecting a certain level of reliability.

\section{Transparency}

Pricing mechanisms in a monopolistic system often are subsidized to appease social policy requirements. However, in a deregulated market, consumers should eventually be able to choose their own retail supplier. In this arrangement, consumers need accurate and transparent information regarding price and service.

\section{Social Policy}

Although government is responsible for social policy, it is recommended that energy policy not be an element of social policy. A newly designed regulatory system can be crafted to synchronize public and private interests.

\section{Equity}

The government as a consequence of deregulation may no longer maintain universal service obligations. Low-income customers may need to be assisted by direct government funding.

\section{Consumer Protection}

It is possible that industrial customers will benefit more from deregulation than residential ones. Regulation will need to be applied to enforce appropriate competition laws.

\section{Pricing Issues}

It is important to manage prices as a country transitions from one power market model to another. Two areas are commonly found: price increases and reduction of employment levels. Price increases may be made more gradual, especially by utilizing subsidies, efficiency improvements, enhanced competition and disbursement of consumer information.

\section{Reform and the Environment}

As a wholesale power market develops to be more competitive, there is more pressure to run plants that have a lower cost of production. It is possible that these lower costs of production plants emit the most harmful contaminants into the environment. Though not intrinsic to the reform process, it is recommended that environmental policy evolve at the same time as economic and social policy.

\section{Regulation}

Market power is a central issue in deregulation, and requires a regulatory regime to constrain non-competitive manipulation of the market. 
Reflecting the theme that suggests that each country, including the APEC members, should conceptualize a reform program designed on one or many models, the APEC energy working group states, "The circumstances of each APEC economy present unique issues and problems in designing regulatory aspects of market reforms. What has succeeded in other economies may not be appropriate in a particular economy in Asia." This is substantiated by the prominence that Russia holds as a case study when looking at APEC area electricity sector deregulation [40].

Indeed, Belyaev, et. al. [41], foreshadowing Arakawa [36], indicates that the interconnection of electric power systems, to broaden power markets, is expanding internationally. The NorthEast Asia region, composed of China, Japan, North and South Korea, and the Far East area of Russia hold the highest potential to design and implement interstate interconnections. The east Siberian area, including the Krasnoyarsk and Irkutsk electric power systems, has a surplus of capacity. This extra capacity is because of reduced exports to the European and Ural part of Russia as the industrial economy has been in decline. Consequently, and for example, energy experts at the Irkutsk, Russia electric utility have concluded that it is possible for an economically efficient interconnection between Irkutsk and China, exporting, respectively, up to $3 \mathrm{GW}$ [41]. Plans such as this are supported by published policies of APEC [42]. Cross-border transmission networks, as planned in APEC, are perceived to strengthen the security, quality and flexibility of energy supply.

Thus, it is important to adopt a market model that has multiple buyers formed immediately after unbundling, in areas such as the CIS. CIS cross-border synchronization is beneficial because it places better use of existing generation capacity, provides emergency assistance options, and harmonizes standards in the areas of safety, ecology, and technology.

It is thought that the economic transition period from socialistic to capitalistic markets, especially in energy, no longer exists. Experience with utilizing institutional models has shown that they often work very differently for the emulator than the emulated.

Wholesale market mechanisms should be able to interface with regulatory frameworks, transmission and distribution planning, and access. This should account for the need to provide cost effective supply from generation to the distribution connecting points.

The primary aim of power system reform should be to improve economic efficiency. The economic milieu of each economy presents unique issues and problems when designing regulatory aspects of market reforms. What has succeeded in other economies may not be appropriate in a particular economy in Asia.

\subsection{The Globalization of Energy Markets in Asia}

Energy market globalization is deepening and broadening, not only through international trade but also through cross-investments, deregulation of domestic markets, and industrial restructuring that links the older energy industries to the new global political economy. This transformation of energy industries and markets is apparent around the world, and it offers great promise in terms of economic efficiency, technology development, and consumer choice. 
The process of energy globalization is uneven, however, and some of its impacts will present new challenges for strategic planners. What new relationships are developing between producers and consumers, and between buyers and sellers? Who are the winners and losers? In a context of opening energy markets, why is there renewed concern about energy security around the world today? What types of security challenges will energy globalization present during the next two decades?

There are varying approaches to energy security in a context of market globalization. The United States supports market-oriented energy policies at home and abroad that open traditionally closed markets to new forms of competition and restructuring. Asia, a region where the United States has vast security stakes and where the most rapid increases in oil and gas imports are projected in the next two decades, deserves special attention. Policymakers in Asia and other countries worry that the market alone will not ensure energy security. The United States has generally pursued energy security on a different track, making Persian Gulf security a high priority.

To promote the cooperation and mutual interdependence that open energy markets require, it will be necessary to explore different approaches to energy security, analyze some of the unintended security risks that globalization of energy markets entails, and draw conclusions about the implications for U.S. security. Although the United States has already made large investments in Asian security, new multilateral approaches will be needed to pre-empt and mitigate the energy-related disruptions that may lie ahead. Defending the sea-lanes, to take an example, will be more important than ever in the future, but ensuring freedom of transit will require new multilateral efforts that cannot be simply subsumed under traditional alliances. Although the United States will have adequate access to energy supplies, it may be drawn into energyrelated disputes, as weak states fragment, and producers and others seek to exert political leverage via energy supplies and infrastructure. Despite the uncertainties and difficulties of multilateral initiatives, it will be necessary to use them to address myriad energy-related security problems that are likely to arise as unintended consequences of energy market globalization. This Section presents the globalization of energy markets in Asia [43-51].

\subsubsection{Energy Challenges in Northeast Asia}

\subsubsection{Recent Progress in Energy Integration in Northeast Asia}

In the IEA [WJL1] programs, Northeast Asia, Figure 16.20, includes Northeast China (Heilongjiang, Liaoning and Jilin Provinces), East Siberia and the Far East of Russia (mainly Sakhalin Islands and Saha Republic), Mongolia, and Democratic People's Republic of Korea (DPRK). These countries and areas form a unique region in terms of energy supply lines together with Japan and Korea.

Recently, there has been increasing interest to integrate this area with various cross-border energy development projects and, in fact, several regional and international organizations have begun to put in serious effort to tackle this issue. Since June 2000, the United Nations Development Plan (UNDP) has held the international program called TRADP (Tumen River Area Development Program) among five Northeast Asian countries (China, Russia, Mongolia, Korea and DPRK) has organized annual meetings among the National Coordinators to 
discuss the cooperative work in energy, trade and investment, transportation, telecommunication and tourism. The UNDP is providing administrative and consultancy service for this series of meetings, and the IEA was invited to become a collaborating organization in the energy part of this program.

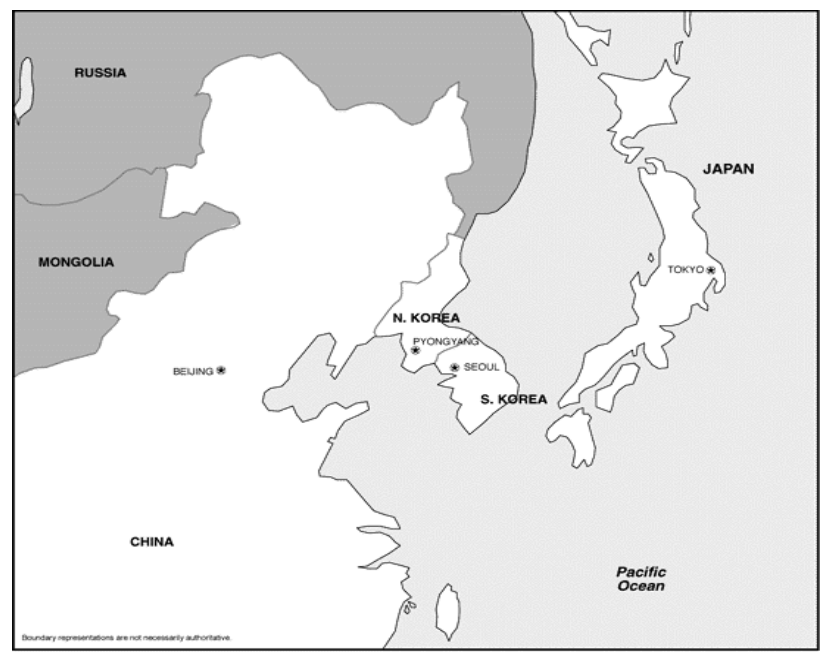

Figure 16.20. The potential Northeast Asia power market

In June 2001, an international symposium on Northeast Asian energy cooperation was held in Seoul jointly by UN/ESCAP (United Nations Economic and Social Commission for Asia and the Pacific), KEEI (Korea Energy Economics Institute), and IEEJ (The Institute of Energy Economics, Japan). In this conference, a necessity to build an inter-governmental communication channel was suggested. Based on this discussion, a senior government officials meeting among Russia, Mongolia, Korea and DPRK was held in Vladivostok on 8-10 April 2005. The IEA was invited as a guest speaker to share the Member countries' experience in energy trade with Russia. A second session of this senior officials meeting was scheduled in November 2005.

In addition to the internal energy cooperation within the Northeast Asian region, the cooperation between ASEAN and Northeast Asian countries is getting stronger. Since the ten member states of ASEAN have limited resources to nourish their own economic development, the partnerships with Japan, China and Korea have great significance. In this case, a collaborative relationship with ASEAN+3 can even benefit DPRK, Mongolia and Far-East Russia as well. There have been continuous talks and meetings since 1999 among these countries not only on energy cooperation but also all possible economic partnerships. These efforts were accelerated by ASEAN+3 Summits and will have substantial impacts on energy security of Northeast Asian region.

Considering that the Northeast Asian region accounts for more than one fifth of the world's energy consumption and is expected to account for one-third of the world's total energy demand increase over the next 20 years, it is certain that the energy integration of this region 
will have a significant impact on world energy security. This is good ground for IEA Secretariat attention to the energy development in this area.

\subsubsection{The On-going Energy Integration Projects in Northeast Asia}

One of the distinguishing features of Northeast Asia is that, in spite of both immense energy demand and abundant energy resources that exist in the region, the region remains segregated. On the demand side, the most critical issue of the three major energy importing countries- Japan, China, and Korea- is their high dependency on imported oil, especially from the Middle East. Therefore, the common denominator for these large energy consuming countries is diversification of the energy sources, i.e., the need to shift from oil to other energy resources such as natural gas and renewables, and to move from Middle East towards other energy suppliers for their energy imports.

On the supply side, the energy reserves in the eastern region of Russia are crucial to Northeast Asia. To date, most discussions of Russian energy have focused on its exports to Europe, but in the last five years, Russia's interest in developing energy relations with its eastern neighbors and potential energy partners has grown. The main reason for this "Russia East" policy is to exploit the abundant natural gas and oil resources in the east of Russia such as Sakhalin Island, Yakutsk, and Irkutsk near Lake Baikal, which could supply Northeast Asia and even the whole Asia-Pacific market.

Under these circumstances and in order to ensure energy security in the region, there have been many private sector efforts to connect these abundant energy resources with the demanding countries. The following are the major ongoing projects and plans in this region. Some of these initiatives are progressing more actively than others and bear a close review.

\subsubsection{Developing International Power Markets in East Asia}

The Greater Mekong sub region (Figure 16.21), Cambodia, Lao People's Democratic Republic, Myanmar, Thailand, Vietnam, and the Yunnan Province of southern China-has significant potential for cross-border power trade. The sub region is well endowed with low-cost hydro resources - the Mekong River Basin is the world's twelfth largest river system - and China, Lao PDR, Thailand and Vietnam have large coal and natural gas reserves. The potential for trade stems from imbalances in costs and in supply and demand between countries in close proximity: the low cost hydro potential is in Lao PDR, Myanmar, and Yunnan Province, but the main markets are Thailand and the more distant Malaysia-Singapore grid about 1,000 kilometers away.

Recent studies comparing scenarios of electricity self-sufficiency in each country with a full trade scenario show that full trade could yield cost savings of at least US\$10.4 billion in 2001-20 and a reduction of airborne pollutants valued at US\$160 million a year (these estimates assume a significant slowing in power demand over the next few years in Thailand as a result of the current financial crisis.) The savings would arise from:

- Lower operating costs due to economic power exchange, postponed and lower investments in generation due to least-cost development of regional energy resources, and reduced spinning reserve costs. 
- Lower coincident peak load (compared with the sum of individual peak loads), mutual access to generation reserves for interconnected systems, a more robust power supply to meet such unexpected events as load growth above forecast or delayed commissioning of generation and transmission projects, and increased system reliability.

- Lower greenhouse gas emissions and other pollutants, largely due to a shift from thermal to hydro generation in the long-term.

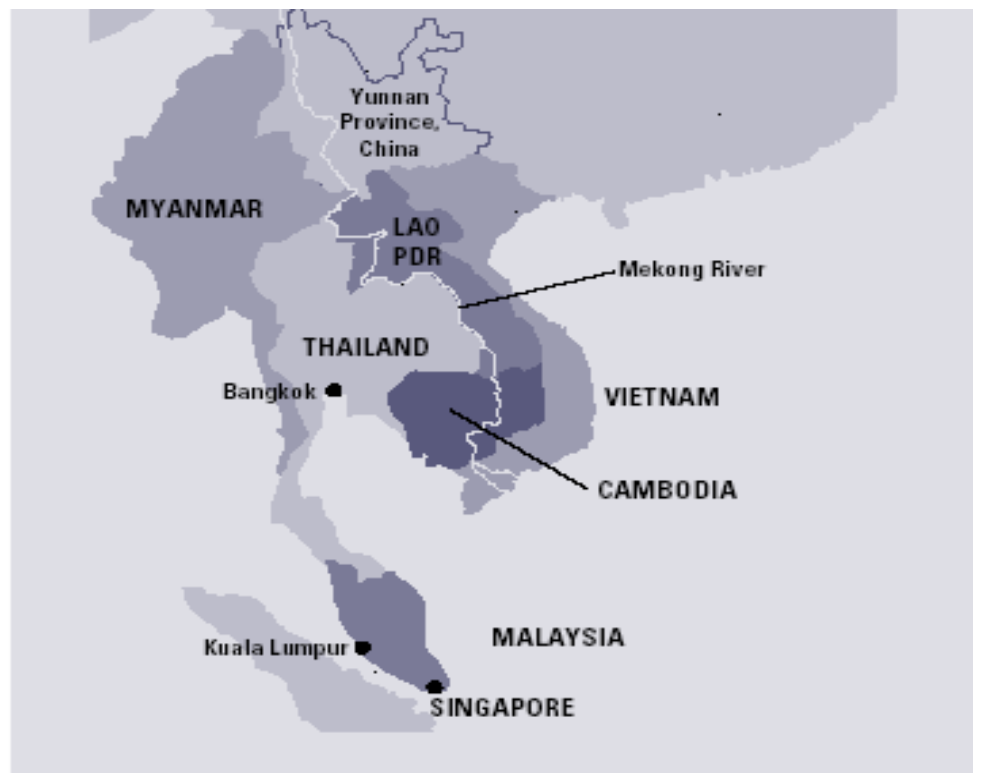

Figure 16.21. The potential East Asian power market

There is growing interest in cross-border bilateral power trade in the sub region, spearheaded by private developers in Lao PDR selling power to Thailand. The government of Thailand has agreed to buy 3,000 MW from these private power developers from 2006, and several independent power producer (IPP) projects are moving ahead. China's Ministry of Electric Power is encouraging studies of the export potential of Yunnan's planned Jing Hong hydropower plant and associated transmission lines to Thailand, through Lao PDR, with the support of the Lao and Thai governments. The Vietnam and Lao governments have signed a memorandum of understanding on purchases of about 2,000 MW of power by 2010.

\subsubsection{Energy Market Globalization}

Does it matter that globalization is unfolding unevenly and that policy priorities for enhancing energy security are defined differently in the United States, Europe, and Asia? Traditionally, analysts have focused on the potential for military conflict over energy resources as the primary threat. Extrapolating 20 years ahead, based on consensus supply-and-demand projections that show sharp increases in Asia's energy requirements; a number of energyrelated issues are likely to generate new types of problems and unintended consequences associated with deepening globalization. To the extent that globalized energy markets more 
deeply integrate economies in the region, investment resources, entrepreneurial skills, and experience in governance will be available to mitigate the downsides. At the same time, U.S. officials responsible for security as well as for economic policy need to anticipate problems - many of them unintended consequences of globalization - that they may be required to address. Focusing on Asia, where there is no overarching, institutionalized security framework and where energy market globalization offers perhaps the biggest un certainties as well as great promise, brings potential problems into sharper view.

Among the countries of the Asia-Pacific Economic Cooperation (APEC) group, electricity demand is projected to increase 60 percent by 2010, with China's electricity demand likely increasing by almost 6.4 percent annually. In India, the International Energy Agency (IEA) forecasts that electricity consumption will be more than double between 1995 and 2010. These forecasts (revised after the Asian economic downturn) imply major additions to generating capacity and to grids. Coal will likely continue to play the major role in electric power generation, but substantial increases in gas-fired generation are expected. Asia now has only limited intercountry electricity trade and pipeline systems. A number of countries, China in particular, have substantial energy resources located far from industrial and population centers.

Most of developing Asia is part of the global energy system, but because of inadequate investment in infrastructure as well as weak political leadership, the connections are in some cases tenuous. Rapid population growth and pressures for economic restructuring and deregulation have already produced some wrenching changes. Twenty thousand miners rioted in Northeast China in early 2000 after an announcement that a large mine had gone bankrupt, and workers were offered a one-time severance package equal to $\$ 68$ per working year. The army was brought in to restore order, but the incident was not reported in the press for weeks. Industrial unrest is rising in China's resources sector, where inefficient plants must be closed in line with government restructuring plans and ambitions to enter the World Trade Organization.

Russia exemplifies another type of political complication associated with market integration. In Russia, the country with the world's largest natural gas reserves, a good portion of which is located in the Far East, there are frequent blackouts. Gazprom cut gas supplies to RAO Unified Energy Systems (UES) recently in response to nonpayment. Gazprom is not investing enough to keep its gas flowing, and UES has warned that its old network of power stations and lines needs $\$ 75$ billion in investment if Russia is to avoid blackouts. Europeans and Asians hoping to import more Russian gas are rightly concerned about supply security in light of Russia's status as a non-signatory of the energy charter, which includes transit provisions.

These examples illustrate the potential political fallout when energy market globalization occurs in developing and transitional economies that lack experience with market competition. As markets and infrastructure are connected across national borders, fuel substitution and economic benefits accrue. At the same time, new vulnerabilities are created. Energy infrastructure such as power grids can be the target of terrorists and opposition groups. These concerns are not unique to developing countries, of course. 
The President's Critical Infrastructure Commission has outlined serious threats to the U.S. energy system from a number of sources - including hostile governments, terrorist groups, and disgruntled employees - as well as accidents.

For some groups in developing economies, the sharp changes in fortune that accompany restructuring and global energy market integration can create a political backlash that threatens the security of neighbors who buy energy from them or import it through their territories. Intense discussions are now under way in Northeast Asia about cooperation in pipelines and high-voltage transmission lines extending from Russia into China. According to some estimates, Eastern Russia could supply half of Northeast Asia's natural gas needs by 2020. These projects offer great promise in meeting energy demand and in hands-on cooperation among countries that have been historical competitors and enemies. The United States and countries in the region need to discuss the security implications of growing and asymmetrical interdependence, however, at an early stage. Joint planning and scenario analysis involving government as well as private sector organizations will be needed to anticipate and mitigate risks. The United States could lend support for discussions involving public officials and private sector representatives from Japan and South Korea, but Russia and China also need to be involved. In addition to high-level discussions on rules of the road for cooperative energy development, there is a need for joint efforts among environmental experts to assess potential effects, among regulatory authorities to discuss harmonization of equipment and industrial standards, and among legal experts to clarify issues such as transit rights and reciprocal tax treatment.

In developing Asia, where energy market integration is uneven, energy demand will grow sharply; because the infrastructure is inadequate and vulnerable, security-related problems are likely to grow. Attacks on energy infrastructure in friendly nations could lead to requests for U.S. assistance - both official and private. U.S. cooperation in the APEC and other regional initiatives to promote common standards and shared infrastructure are, in this light, a good investment. Although U.S. support for APEC energy market liberalization initiatives has been strong, energy security concerns have been treated with less urgency. U.S. industry and government could make this a higher priority and share expertise for assessing and mitigating risks.

A second dimension of uneven globalization-Asia's growing dependence on Middle East oil-also will present new challenges. The United States has made great investments in Persian Gulf security and has gone to war to ensure the stability of the region and its oil production. In the future, the narrow, shallow Straits of Malacca and the sea-lanes between the Middle East and Asia will be more congested with tankers and other ships carrying fuel and commodities. Today, 90 percent of Japan's oil imports and most of South Korea and Taiwan's oil imports flow through these waters. More than 200 vessels pass through the Malacca, Sundra, and Lombok Straits and the South China Sea daily. In 1994, more than \$1 trillion in international trade passed through these waters, which have seen an increase in serious accidents since the early 1990s. Piracy, kidnapping, and other acts of violence by non-state actors, such as leftwing rebels in the Philippines, are also on the rise. China has fortified small islets in the South China Sea with fort-like structures, and the number of incidents involving fishing and naval vessels from Southeast Asian countries has increased. 
Although some argue that territorial chokepoints such as these narrow water passageways are no longer security concerns in an age of globally integrated electronic markets that permit rerouting of cargo and fuel switching, securing freedom of the sea-lanes may well be more of a security challenge in the future. Competing claims among six claimants to the Spratly Islands, differing interpretations of the United Nations Law of the Sea, and the inability of the International Maritime Organization to establish safety and environmental standards of sufficiently high quality all contribute to a sort of maritime anarchy. At the urging of the Philippines and other Southeast Asian states, the Association of Southeast Asian Nations (ASEAN) Regional Forum has agreed to take up the question of a code of conduct for the South China Sea; however, China opposes legally binding agreements and prefers to deal separately with each country. Other countries favor demilitarization and joint development, with the geographically closest claimant country taking stewardship over disputed areas. In this context, the potential for military conflict remains significant. By supporting efforts of regional states to address these issues, the United States can add momentum and expertise.

In the future, accidents and acts of terrorism and piracy will be even more likely throughout the region. Some have called for a change in the transit passage law enshrined by the Law of the Sea separating commercial and military traffic. The objective would be increased regulation of commercial vessels in the Straits of Malacca to ensure navigation safety without affecting military or government vessels. Such a regime would involve not only the key states but also shipping concerns and user states such as Japan, China, and the United States. A working group has led another approach on maritime security cooperation of the Council for Security Cooperation in the Asia Pacific, a nonofficial organization that provides input to the ASEAN Regional Forum. The working group has developed guidelines for maritime cooperation and plans to examine the Law of the Sea to identify areas that need clarification in order to ensure maritime security in South Asia. These efforts suggest that addressing maritime security problems in Asia will be a challenging task, but arguably a good investment in preventive diplomacy. Cleaning up after a major oil spill and relief efforts to deal with terrorism or piracy could be much more costly after the fact.

Another way to address vulnerabilities in energy transportation through the sea-lanes is to develop regional emergency response mechanisms. Japan, Australia, and New Zealand [WJL1] are the only Asian members of the IEA, although South Korea is following IEA activities closely, and programs for nonmember states such as China have recently expanded. Asia lacks a viable region-wide program of emergency response or oil stockpiles. Although the impulse is strong for many of the Asian countries to pursue old-style resource diplomacy to secure supplies of Middle East oil, a more effective approach would be to build cooperative emergency response measures.

Market-oriented approaches can also contribute to solutions. Asian countries could permit cross-investment in downstream facilities so that refinery operations could be streamlined and efficiencies improved, encouraging Middle East countries to consider establishing storage facilities in the region. In addition, government involvement in emergency response and stockpile development is needed. American political support, technical expertise, and approvals to use international development assistance funding would help significantly in addressing energy security concerns in Asia and in bolstering the confidence and mutual trust required to sustain energy market liberalization policies over the long haul. 
International corporate linkages in Asian energy markets are most extensive in the upstream resource exploration and development areas. Japanese firms have for years been mining coal in Australia, developing natural gas resources in Indonesia, and purchasing oil from China. With greater openness come new possibilities. Tokyo Electric Power has stakes in new power-generating ventures in Malaysia and Vietnam. Enron has teamed up with ORIX Leasing to compete in Japan's energy services and electric power markets. Marubeni, a Japanese trading company, and Sithe Energies, an independent U.S. power producer, plan to buy power plants and market electricity in Japan. Gas and electric power are the focus of networks of growing international joint ventures that include firms from many Asian countries, as well as from the United States.

These corporate linkages today extend further and deeper into the domestic economies and, in some cases, can stimulate market-oriented corporate restructuring and advanced technology development. They can also lead to new security challenges. In 1996, Japan imported almost one-fifth of its natural gas from Indonesia, a country where violent independence movements have threatened central authority in some regions. Electric power, gas, and steel companies have long-term contracts for liquefied natural gas (LNG) imports from Indonesia that stretch more than a decade ahead in some cases. Two-fifths of Indonesia's LNG exports come from Aceh, at the western end of Sumatra. Aceh is overwhelmingly Islamic; its rural people resent the wealth of the Javanese who run the industrial enclave. Disputes and violence have erupted. The potential fragmentation of energy- and resource-rich regions poses problems not only for central government but also for the importers whose investments become vulnerabilities. The United States, Japan, and others have an interest in developing multilateral approaches toward assistance that leverage the resources of the international community and address the basic grievances that have led to strife and tension.

Advanced technology is diffusing through energy development, presenting another doubleedged sword from a security perspective. Japan, South Korea, Russia, China, Taiwan, India, and Pakistan have commercial nuclear power programs, and four of these states have tested and/or developed nuclear weapons. For Japan, nuclear power has been the central pillar of its energy policy - seen as Japan's only hope for gaining a degree of autonomous control (through technology indigenization) and for meeting environmental commitments. However, the serious criticality accident that took place recently at a fuel fabrication plant shook Japan's energy policy leadership enough for the government to announce a comprehensive review. Japan's ambitious plan to develop the complete fuel cycle has proved to be expensive and technically difficult. Such problems aside, Asia has become the new center of gravity for the global nuclear industry, as additions to capacity in this region are projected to make up three-quarters or more of the world's total over the next two decades.

For safety, environmental, and nonproliferation reasons, advanced technology cooperation in energy among Asian nations is essential. Working with other nations around the world, the industrial operators and research institutions of Asia need to develop a stronger safety culture. In addition, governments will need to work to strengthen nonproliferation norms (a very difficult task in South Asia) and to build cooperation in material protection, accounting, and export controls. Weapons of mass destruction proliferation are clearly a major threat to the stability of a region where the security framework is weak. Two of the benefits 
of addressing the North Korea problem have been an expansion of security cooperation between Japan and South Korea and a broadening of dialogue involving China.

Other forms of cooperation are also needed to make the most of new technologies that are coming on stream. They include micro turbines and fuel-efficient vehicles that offer promise not only for industrialized countries but also for many developing nations. Regulatory barriers, as well as established business practices, may present obstacles to the application of new equipment and systems. Government leadership in eliminating regulatory obstacles and in supporting international partnerships could speed up penetration and assimilation of technologies - with environmental gains for all concerned.

Thus, as energy market globalization proceeds in Asia, the likelihood that the United States will be forced to deal with threats that stem from unintended consequences will increase. Multiple actors will be involved, and solutions will in most cases need to be constructed - at least in the near term - in the absence of established frameworks and institutions.

The potential security risks stem in large part from the unintended consequences of uneven globalization in a context of partial market liberalization. In the current transitional phase, critical choices are being made about financial investments, partnerships, technology development, and fuels that will affect evolving and multidimensional interdependent relations among actors. Addressing energy security concerns, rather than dismissing them, is a requirement for promoting market oriented policies.

In this fluid context, the United States should take pre-emptive action, investing resources in preventive diplomacy and building security communities on specific issues in order to avoid the need for military force deployment down the road. Despite the uncertainties and inadequacies of multilateral approaches, there is really no alternative. The investments will be costly (not so much in terms of hardware, but in terms of time) and will challenge the skills of strategists trained to deal with more traditional security threats. Security specialists will need to work more closely with economic policymakers and the private sector, bridging the traditional separation between security and economic policy domains.

Asia offers the most striking example of both the potential risks of neglecting these issues and the tremendous gains that can come from devising new ways to address the concrete problem of energy security. China and India, the emerging new energy giants, will need assistance in meeting energy requirements and addressing concerns about energy security if they are to contribute to, rather than detract from, Asian security. The United States will need to work proactively with them and with other countries in the region, forming new communities to deal with specific energy security concerns. In many cases, doing so will require focused dialogue not only with close allies and friends but also with other countries. Issues that require attention include disputes over energy-rich areas such as the South China Sea, the absence of an emergency response program in Asia to deal with oil supply interruptions, and the need for cooperation in resource development and efficient and environmentally sound energy use in the Russian Far East and China, as well as the potential for expanded energy cooperation involving South and North Korea, if progress continues in building trust and reducing threats on the Korean Peninsula. 


\subsection{Acknowledgements}

Nikolai I. Voropai, Professor, Corresponding Member of RAS, Director of Energy Systems Institute, Irkutsk, Russia has prepared and coordinated this Chapter. Contributors include colleagues at the Institute and Members of the IEEE PES W.G. on Asian and Australian Electricity Infrastructure.

\subsection{References}

[1] "Open Access in Inter-State Transmission", Central Electricity Regulatory Commission, New Delhi, India, Nov. 2003.

[2] "Electricity Act 2003", Ministry of Power, Government of India, New Delhi, India, June 2003.

[3] Mukhopadhyay, S., K. Dube, S., "Status of Power Exchange in India: Trading, Scheduling, and Real Time Operation of Regional Grids", in Proc. 2005 IEEE PES General Meeting, San Francisco.

[4] Palamarchuk, S., Podkovalnikov, S., Voropai, N., "Getting the Electricity Sector on Track in Russia", The Electricity Journal, USA, October, 2001

[5] Lamourex, M.A., Palamarchuk, S.I., Voropai, N.I. "Current Developments in Russian Power Industry Restructuring", Proc. 2003 Intern. Workshop "Liberalization and Modernization of Power Systems: Congestion Management Problems", Irkutsk, Russia, Aug. 11-14, 2003.

[6] Reshetov, V.I., Semenov, V.A., Lisitsin, N.V., Unified Electric System in Russia at the Edge of Centuries. Current State and Perspectives of Development. Moscow: ENAS Publishers, 2002 (in Russian).

[7] Voropai, N.I." Investment and Development of Electric Power Industry in Market Environment", Proc. of the POWERCON'2002 Conf., Vol. 1, Kunming, China, Oct. 13-17, 2002.

[8] http://old.rao-ees.ru/en/news/pr/show.cgi?020404udal.htm

[9] Voropai, N.I., Palamarchuk, S.I., Podkovalnikov, S.V., "Power Industry in Russia: Stateof-the-Art and Reformation Process", Proc. of 4-th Intern. World Energy System Conf. (WESC-2002), Toryo, Japan, March 4-6, 2002.

[10] State Power website, http://www.sp.com.cn

[11] Wu, F. F., Fu, Shuiti, "China's Future in Electric Energy", IEEE Power \& Energy Magazine, 2005, Vol. 3, No. 4, pp. 32-38.

[12] State Power Information website, http://www.sgcc.com.cn/

[13] China Electric Power News, October 19, 2005.

[14] China Power News website, http:/ / www.cpnn.com.cn

[15] "Report on 2005 China Electricity Markets and Electricity Price"

[16] China Electric Power News, August 19, 2005.

[17] China Energy website, http://www.china5e.com.cn

[18] China Power System Information website, http://www.chinarein. com

[19] Xizheng, Zhao, "Optimize the Power Source Structure and Upgrade the Power Industry" China Industry News, 2005, No. 10.

[20] "Detailed design of the Japanese desirable restructuring of electric power industry", METI, June 2004 (in Japanese).

[21] Materials submitted to the "Subcommittee on the evaluation of the Institutional Reforms" METI, 2005 (in Japanese)

[22] "ATC of the interconnected transmission lines (Prospect of future 10 years)" , ESCJ , June 2005 (in Japanese) 
[23] Schweppe, F.C., Caramanis, M., Tabors, R., Bohn, R., Spot Pricing of Electricity, Kluwer Academic Publishers, Boston, 1988.

[24] Hogan, W.W., Contract Networks for Electricity Power Transmission. Journal of Regulatory Economics, Vol. 4, 1992.

[25] 25Leveque, F., Transport Pricing of Electricity Networks, Kluwer Academic Publishers, Boston, 2003.

[26] Wu, F.F., Ni, Y., Wei, P., Power Transfer Allocation for Open Access Using Graph Theory-Fundamentals and Applications in System without Loopflow. IEEE Transactions on Power Systems, Vol. 15, No. 3, 2000.

[27] Lee, B., Song, H., Kwon, S. H., Jang, G., Kim, J. H., Ajjarapu, V., "A study on determination of interface flow limits in the KEPCO system using modified continuation power flow (MCPF)," IEEE Trans. Power Syst., 2002, Vol. 17, No.2.

[28] Jeong, H.S., Moon, Y.H., Oh, T.K., Hur, D., Park, J.K., "Status and Perspective of Transmission Pricing Scheme in Korean Electricity Market," CIGRE/IEEE PES International Symposium, Session 2a, Seoul, Korea, 2005.

[29] CIS Electric Power Council. "Current Status and Development of CIS Countries' Power Sectors," presented for the Energy Charter Seminar Liberalizing Trade and Investment in the Eurasian Power Sector, Brussels, 2002.

[30] Lovei, L., "The Single-Buyer Model," Public Policy for the Private Sector. Washington, D.C., The World Bank Group, 2000.

[31] European Bank, Power Sector Regulatory Reform in Transition Economies: Progress and Lessons Learned, London, European Bank for Reconstruction and Development, 2003.

[32] International Monetary Fund (IMF), Cross-Border Issues in Energy Trade in the CIS Countries, Washington, D.C., IMF European II Department, 2002.

[33] Energy Charter Secretariat (ECS), Kazakhstan Investment Climate and Market Structure in the Energy Sector, Brussels, Belgium, ECT, 2002.

[34] Eurelectric, Electricity Sector Reform: The Pan-European, CIS and Mediterranean Dimension, Brussels, Belgium, Union of the Electricity Industry - Eurelectric, 2003.

[35] Hirschhausen, C. van., Waelde, T., "The End of Transition - An Institutional Interpretation of Energy Sector Reform in Eastern Europe and the CIS," MOCT Economic Policy in Transitional Economies, 2001.

[36] Arakawa, F., "Restructuring Needed for PGI," presented at the Workshop on Power Grid Interconnection (PGI) in Northeast Asia, Shenzhen, China, 2002.

[37] Asia-Pacific Economic Cooperation (APEC). (2004) About APEC. [online]. Available: http://www.apecsec.org.sg/apec/about_apec. html

[38] Asia-Pacific Economic Cooperation (APEC), Electricity Reform in APEC Economies - The Way Ahead, Eter Smiles \& Associates, Resource Law Inter-national, APEC Energy Working Group, 2003.

[39] Asia-Pacific Economic Cooperation (APEC), Strengthening Operational Aspects of APEC Energy Micro-Economic Reform, Manual of Strategic Principles, APEC Energy Working Group, Singapore: APEC Secretariat, 2001.

[40] Asia-Pacific Economic Cooperation (APEC), Electricity Sector Deregulation in the APEC Region, Asia Pacific Energy Research Centre, Institute of Energy Economics, Japan, 2000. 
[41] Belyaev, L. S., Voropai, N.I., Podkovalnikov, S.V., Shutov, G.V, “Prerequisites and Directions in Formation of North-East Asian Power System," Perspectives in Energy, 19971998, Vol. 4.

[42] Asia-Pacific Economic Cooperation (APEC), Cross-Border Power, APEC Energy Working Group, APEC Secretariat, Singapore, 2002.

[43] IEA ‘01, 2001 World Development Indicators.

[44] Neff, T. L., "Improving Energy Security in Pacific Asia: Diversification and Risk Reduction for Fossil and Nuclear Fuels," Centre for International Studies, Massachusetts Institute of Technology, 1997.

[45] Ofgem '99, The new electricity trading arrangement, Volume 2, July 1999.

[46] OECD ‘98, Energy Balances of OECD Countries, IEA/OECD Paris, 1998.

[47] UN Energy Statistics, several volumes between 1970 and 1997.

[48] International Energy Outlook, 1999.

[49] Enron Energy Outlook 1999-2020, 9.

[50] Asia Pacific Energy Research Center, APEC Energy Demand and Supply Outlook (Tokyo, Updated September 1998).

[51] Harris, M. C.Chapter 12, "The Globalization of Energy Markets," Global Century: Globalization and National Security, 2001, Vol. I \& II. 


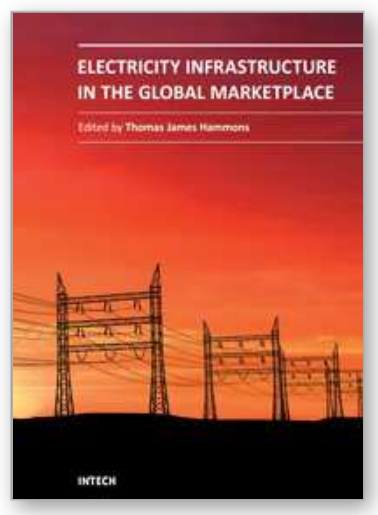

\author{
Electricity Infrastructures in the Global Marketplace \\ Edited by
}

ISBN 978-953-307-155-8

Hard cover, 802 pages

Publisher InTech

Published online 27, June, 2011

Published in print edition June, 2011

This book discusses trends in the energy industries of emerging economies in all continents. It provides the forum for dissemination and exchange of scientific and engineering information on the theoretical generic and applied areas of scientific and engineering knowledge relating to electrical power infrastructure in the global marketplace. It is a timely reference to modern deregulated energy infrastructure: challenges of restructuring electricity markets in emerging economies. The topics deal with nuclear and hydropower worldwide; biomass; energy potential of the oceans; geothermal energy; reliability; wind power; integrating renewable and dispersed electricity into the grid; electricity markets in Africa, Asia, China, Europe, India, Russia, and in South America. In addition the merits of GHG programs and markets on the electrical power industry, market mechanisms and supply adequacy in hydro-dominated countries in Latin America, energy issues under deregulated environments (including insurance issues) and the African Union and new partnerships for Africa's development is considered.

Thomas James Hammons (Fellow IEEE 1996) received the B.Sc. degree in Engineering (1st Class Honors), and the DIC, and Ph.D. degrees from Imperial College, London, UK He is a member of the teaching faculty of the School of Engineering, University of Glasgow, Scotland, UK. He was Professor of Electrical and Computer Engineering at McMaster University, Hamilton, Ontario, Canada in 1978-1979. He is the author/co-author of over 440 scientific articles and papers on electrical power engineering and is Editor of a book on Renewable Energy that was published by INTECH in December 2009. He has lectured extensively in North America, Africa, Asia, and both in Eastern and Western Europe.

Dr Hammons is Past Chair of the United Kingdom and Republic of Ireland (UKRI) Section IEEE and Past Chair of International Practices for Energy Development and Power Generation of IEEE. He is also a Past Chair of the IEEE PES Task Force on harmonizing power-engineering standards worldwide and Past Permanent Secretary of the International Universities Power Engineering Conference. He is a Chartered Engineer (CEng) and a registered European Engineer in the Federation of National Engineering Associations in Europe.

\title{
How to reference
}

In order to correctly reference this scholarly work, feel free to copy and paste the following:

T. J. Hammons (2011). Power Markets of Asian Countries in the International Markets Environment, Electricity Infrastructures in the Global Marketplace, (Ed.), ISBN: 978-953-307-155-8, InTech, Available from:

http://www.intechopen.com/books/electricity-infrastructures-in-the-global-marketplace/power-markets-of-asiancountries-in-the-international-markets-environment 
open science / open minds

InTech Europe

University Campus STeP Ri

Slavka Krautzeka 83/A

51000 Rijeka, Croatia

Phone: +385 (51) 770447

Fax: +385 (51) 686166

www.intechopen.com
InTech China

Unit 405, Office Block, Hotel Equatorial Shanghai

No.65, Yan An Road (West), Shanghai, 200040, China

中国上海市延安西路65号上海国际贵都大饭店办公楼 405 单元

Phone: +86-21-62489820

Fax: +86-21-62489821 
(C) 2011 The Author(s). Licensee IntechOpen. This chapter is distributed under the terms of the Creative Commons Attribution-NonCommercialShareAlike-3.0 License, which permits use, distribution and reproduction for non-commercial purposes, provided the original is properly cited and derivative works building on this content are distributed under the same license. 